\title{
The role of ENPP1/PC-1 in osteoinduction by calcium phosphate ceramics
}

Citation for published version (APA):

Othman, Z., Fernandes, H., Groot, A. J., Luider, T. M., Alcinesio, A., Pereira, D. D. M., Guttenplan, A. P. M., Yuan, H., \& Habibovic, P. (2019). The role of ENPP1/PC-1 in osteoinduction by calcium phosphate ceramics. Biomaterials, 210, 12-24. https://doi.org/10.1016/j.biomaterials.2019.04.021

Document status and date:

Published: 01/07/2019

DOI:

10.1016/j.biomaterials.2019.04.021

Document Version:

Publisher's PDF, also known as Version of record

Document license:

Taverne

Please check the document version of this publication:

- A submitted manuscript is the version of the article upon submission and before peer-review. There can be important differences between the submitted version and the official published version of record.

People interested in the research are advised to contact the author for the final version of the publication, or visit the DOI to the publisher's website.

- The final author version and the galley proof are versions of the publication after peer review.

- The final published version features the final layout of the paper including the volume, issue and page numbers.

Link to publication

\footnotetext{
General rights rights.

- You may freely distribute the URL identifying the publication in the public portal. please follow below link for the End User Agreement:

www.umlib.nl/taverne-license

Take down policy

If you believe that this document breaches copyright please contact us at:

repository@maastrichtuniversity.nl

providing details and we will investigate your claim.
}

Copyright and moral rights for the publications made accessible in the public portal are retained by the authors and/or other copyright owners and it is a condition of accessing publications that users recognise and abide by the legal requirements associated with these

- Users may download and print one copy of any publication from the public portal for the purpose of private study or research.

- You may not further distribute the material or use it for any profit-making activity or commercial gain

If the publication is distributed under the terms of Article $25 \mathrm{fa}$ of the Dutch Copyright Act, indicated by the "Taverne" license above, 


\title{
The role of ENPP1/PC-1 in osteoinduction by calcium phosphate ceramics
}

\author{
Ziryan Othman ${ }^{\mathrm{a}}$, Hugo Fernandes ${ }^{\mathrm{b}}$, Arjan J. Groot ${ }^{\mathrm{c}}$, Theo M. Luider ${ }^{\mathrm{d}}$, Alessandro Alcinesio ${ }^{\mathrm{e}}$, \\ Daniel de Melo Pereira ${ }^{\mathrm{a}}$, Alexander P.M. Guttenplan ${ }^{\mathrm{a}}$, Huipin Yuan ${ }^{\mathrm{a}}$, Pamela Habibovic ${ }^{\mathrm{a}, *}$ \\ ${ }^{a}$ Department of Instructive Biomaterials Engineering, MERLN Institute for Technology-Inspired Regenerative Medicine, Maastricht University, Universiteitssingel 40, 6229 \\ ER, Maastricht, the Netherlands \\ ${ }^{\mathrm{b}}$ Faculty of Medicine, University of Coimbra, Health Science Campus, Central Unit, Azinhaga de Santa Comba, 3000-354, Coimbra, Portugal \\ ${ }^{\mathrm{c}}$ Department of Radiation Oncology (MaastRO), GROW - School for Oncology \& Developmental Biology, Maastricht University, Universiteitssingel 50, 6229 ER \\ Maastricht, the Netherlands \\ ${ }^{\mathrm{d}}$ Laboratory of Neuro-Oncology and Clinical and Cancer Proteomics, Department of Neurology, Erasmus University Medical Center, Dr. Molewaterplein 50 , 3015 GE \\ Rotterdam, the Netherlands \\ ${ }^{\mathrm{e}}$ Department of Chemistry, Chemistry Research Laboratory, University of Oxford, 12 Mansfield Rd, OX1 3TA, Oxford, UK
}

\section{A R T I C L E IN F O}

\section{Keywords:}

Osteoinduction

Calcium phosphate ceramics

Bone regeneration

Human mesenchymal stromal cells

Ectonucleotide pyrophosphatase/

phosphodiesterase 1

\begin{abstract}
A B S T R A C T
In the past decade, calcium phosphate ( $\mathrm{CaP}$ ) ceramics have emerged as alternatives to autologous bone grafts for the treatment of large, critical-sized bone defects. In order to be effective in the regeneration of such defects, ceramics must show osteoinductive behaviour, defined as the ability to induce de novo heterotopic bone formation. While a set of osteoinductive CaP ceramics has been developed, the exact processes underlying osteoinduction, and the role of the physical and chemical properties of the ceramics, remain largely unknown. Previous studies have focused on the role of the transcriptome to shed light on the mechanism of osteoinduction at the mRNA level. To complement these studies, a proteomic analysis was performed to study the behaviour of hMSCs on osteoinductive and non-osteoinductive CaPs. The results of this analysis suggest that plasma cell glycoprotein 1 (PC-1), encoded by the ectonucleotide pyrophosphatase/phosphodiesterase 1 (ENPP1) gene, plays a key role in the process of osteoinduction by $\mathrm{CaP}$ ceramics. Validation experiments have confirmed that indeed, the mRNA expression of ENPP1 and the production of PC-1 are higher on osteoinductive than on nonosteoinductive CaP ceramics, a trend that was also observed for other osteogenic markers such as bone morphogenetic protein 2 (BMP2) and osteopontin (OPN), but not for alkaline phosphatase (ALP). Our results also showed that the expression of PC-1 is restricted to those cells which are in direct contact with the CaP ceramic surface, plausibly due to the localised depletion of calcium and inorganic phosphate ions from the supersaturated cell culture medium as CaP crystallises on the ceramic surface. Replicating the surface of the osteoinductive ceramic in polystyrene resulted in a significant decrease in ENPP1 expression, suggesting that surface structural properties alone are not sufficient to induce ENPP1 expression. Finally, knocking down ENPP1 expression in hMSCs resulted in increased BMP2 expression, both at the mRNA and protein level, suggesting that ENPP1 is a negative regulator of BMP-2 signalling. Taken together, this study shows, for the first time, that ENPP1/PC-1 plays an important role in CaP-induced osteogenic differentiation of hMSCs and thus possibly osteoinduction by $\mathrm{CaP}$ ceramics. Furthermore, we have identified a crucial role for the interfacial (chemical) events occurring on the CaP ceramic surface in the process of osteoinduction. This knowledge can contribute to the development of new bone graft substitutes, with improved osteoinductive potential.
\end{abstract}

\section{Introduction}

Due to a growing world population, improved quality of life, and increased life expectancy, the incidence of large, critical-sized bone defects is increasing. These defects, caused by trauma, infection, or resection of tumours, are unable to regenerate without clinical intervention [1]. Currently, the standard intervention takes the form of implantation of bone harvested either from elsewhere in the patient (an autograft) or from a donor (an allograft). These methods have serious disadvantages, including limited availability and the risk of infection and of complications from the second surgery required to harvest bone for autografting. Therefore, they are steadily being replaced by

\footnotetext{
* Corresponding author.

E-mail address: p.habibovic@maastrichtuniversity.nl (P. Habibovic).
} 
alternative methods, particularly involving the use of synthetic bone graft substitutes [2]. In contrast to autografts or allografts, synthetic substitutes have lower health risks, essentially unlimited availability, and are relatively inexpensive to produce and store. However, in order to fully replace natural bone grafts, these substitutes must also at least match their efficacy in promoting the healing of large bone defects. This efficacy depends largely on the osteoinductive potential of the materialthat is, its ability to trigger differentiation of undifferentiated stem and/ or progenitor cells into the osteogenic lineage, resulting in de novo bone formation $[3,4]$.

Calcium phosphate $(\mathrm{CaP})$ ceramics are now the leading alternative to natural bone grafts, as they closely resemble natural bone mineral, and exhibit excellent biocompatibility, osteoconductivity and bonebonding properties [5,6]. Moreover, some CaP ceramics have been shown to possess intrinsic osteoinductivity due to their physical and chemical properties. A range of $\mathrm{CaP}$ ceramics, including beta-tricalcium phosphate ( $\beta$-TCP) [7], hydroxyapatite (HA) [8], biphasic calcium phosphate combining $\beta$-TCP and HA [9], carbonated apatite [10], octacalcium phosphate [11], and dicalcium phosphate dihydrate [12], have been shown to induce heterotopic bone formation, the defining characteristic of osteoinductivity, in a variety of in vivo models. However, the mechanism by which these materials elicit this biological response remains poorly understood, and it is not yet known exactly which physical or chemical properties are necessary or sufficient for osteoinduction.

In order to understand the osteoinduction mechanism, researchers have hitherto focused on the role of endogenous factors such as bone morphogenetic proteins (BMPs) [13,14], to date the best known osteoinductive growth factors [15]. Several studies have suggested that the inflammatory response plays an important role [16,17]. It is clear that some combination of physical and chemical properties of the material is required for osteoinduction - chemically identical ceramics can show different degrees of osteoinduction depending on their surface microstructure $[3,18,19]$, while almost all known osteoinductive materials contain calcium phosphates, suggesting an important role for surface chemistry. The different mechanisms proposed for osteoinduction by biomaterials, and the role of specific material properties in each of these mechanisms, are described in recent reviews [20,21]. Very recently, a new mechanism has been suggested whereby osteoinduction is triggered by a localised depletion of calcium and phosphate ions from body fluid which is normally supersaturated with respect to these ions [22], in contrast to previously suggested mechanisms based on a localised increase in dissolved calcium and phosphate concentration close to a CaP-containing material.

In a recent study in our lab, we investigated how a series of biomaterials with known osteoinductive potential modulated the transcriptome of osteoblast-like MG63 cells [23]. We correlated transcriptomic changes with individual properties, thus identifying subsets of genes controlled either by physical surface structure or by chemical composition of the ceramics. This study yielded important information on the cell response to osteoinductive materials at the mRNA level, but the protein interactions involved in this response remain unknown.

To obtain an insight into the interaction of cells with osteoinductive ceramics at the protein level, we investigated the response of bone marrow-derived human mesenchymal stromal cells (hMSCs) to four CaP ceramics with known osteoinductive potential by performing a fullproteome analysis. Two of the ceramics used (HA and BCP1300) were known not to be osteoinductive, while the other two (TCP and BCP1150) were known to be osteoinductive. Note that BCP1150 and BCP1300 are chemically identical and differ only in their surface microstructure.

Based on this analysis, we identified a set of 1090 proteins that are expressed differentially on osteoinductive versus non-osteoinductive $\mathrm{CaP}$ ceramics. From these proteins, we identified plasma cell glycoprotein 1 (PC-1) as a protein of interest for further studies. PC-1 is a type II transmembrane glycoprotein, encoded by the ectonucleotide pyrophosphatase/phosphodiesterase 1 (ENPP1) gene, which is involved in the regulation of tissue mineralisation. PC-1 controls phosphate homeostasis, mainly by hydrolysing adenosine triphosphate (ATP) into adenosine monophosphate (AMP) and pyrophosphate (PPi) [24], though it also hydrolyses ATP to adenosine diphosphate (ADP) and inorganic phosphate $(\mathrm{Pi})$ to a much lesser extent.

It has been suggested that the balance between extracellular Pi and $\mathrm{PPi}$ is involved in the control of tissue calcification, as excess PPi results in decreased bone mineralisation, while PPi deficiency results in excess mineral formation [25]. Therefore, the production of PPi by PC-1 can be considered to negatively regulate tissue mineralisation [26]. In vivo, bone mineral initially forms by the spontaneous precipitation of calcium and phosphate to form crystalline HA in the matrix vesicles (MVs) of osteoclasts. These are organelles from which PPi is excluded, and where if necessary additional Pi can be formed by the hydrolysis of organic phosphate compounds by phosphoethanolamine/phosphochioline phosphatase (PHOSPHO1). Crystals of HA formed in the MVs then enter the extracellular fluid, where they can nucleate further HA crystallisation. This further crystallisation is negatively regulated by $\mathrm{PPi}$, which is transported out of cells by the ANK (ankyloses protein) $[27,28]$. Mutations in ENPP1 or ANK have been shown to cause hypermineralisation disorders in mice [27,29], both due to a deficiency of extracellular PPi and (in the case of ENPP1) due to an interaction with Hedgehog signalling.

Given the role of ENPP1 and its product PC-1 both in orthotopic bone development and in the regulation of heterotopic mineralisation, we aimed to elucidate its role in the response of hMSCs to the presence of osteoinductive $\mathrm{CaP}$ ceramics, and to define the role of individual material properties in eliciting this response.

\section{Materials and methods}

All reagents were obtained from appropriate commercial suppliers and used as received without further purification unless otherwise stated.

\subsection{Calcium phosphate ceramics}

The CaP ceramic particles used in this study had a diameter of 2-3 mm. Hydroxyapatite (HA), beta-tricalcium phosphate (TCP), and two biphasic calcium phosphates consisting of HA and TCP sintered at $1150{ }^{\circ} \mathrm{C}$ (BCP1150) and $1300^{\circ} \mathrm{C}(\mathrm{BCP} 1300)$, were produced using a procedure described previously [30]. Briefly, HA particles were produced from commercially available HA powder (Merck Eurolab BV, Amsterdam, the Netherlands) by dual-phase mixing as previously described and sintered at $1250^{\circ} \mathrm{C}$ for $8 \mathrm{~h}$. TCP particles were prepared from TCP powder (Plasma Biotal, Plasma Coating Ltd., Tideswell, UK) using the $\mathrm{H}_{2} \mathrm{O}_{2}$ method and sintered at $1100{ }^{\circ} \mathrm{C}$. The two BCP ceramics were prepared from a combination of TCP powder (Plasma Biotal) and calcium-deficient apatite powder (produced in-house) using the same method and sintered at $1150{ }^{\circ} \mathrm{C}$ and $1300{ }^{\circ} \mathrm{C}$ to produce BCP1150 and $\mathrm{BCP} 1300$ respectively.

Ceramic discs with a thickness of $1 \mathrm{~mm}$ were produced from ceramic cylinders produced in-house using the same methods as above with a diameter of $9 \mathrm{~mm}$ using a diamond saw microtome (SP-1600, Leica, Wetzlar, Germany). All ceramic materials were sterilised by autoclaving before use.

\subsection{Collagen coating of CaP ceramics}

Rat tail collagen type I (Fisher Scientific, Landsmeer, the Netherlands) was diluted in $0.02 \mathrm{M}$ acetic acid to a final concentration of $50 \mu \mathrm{g} / \mathrm{mL}$ and sterilised by $0.2 \mu \mathrm{m}$ filtration. Sterile ceramic discs were dipped into the collagen solution for $10 \mathrm{~s}$, air-dried for $1 \mathrm{~h}$ at room temperature and gently washed twice with sterile PBS. 


\subsection{Structural replicas of ceramics in polystyrene}

Polystyrene replicas of the ceramic discs were fabricated by replica moulding using a polydimethylsiloxane (PDMS) mould, following a method similar to those described earlier [31-33]. In short, the PDMS mould was prepared by casting a 10:1 w/w mixture of PDMS base and crosslinker (Sylgard 184, Dow Corning, Midland, MI, USA) over a ceramic disc on a glass slide and cured at $80^{\circ} \mathrm{C}$ for $2 \mathrm{~h}$. Polystyrene pieces with a size of approximately $2 \times 2 \mathrm{~cm}$ were cut from the bottom of a Petri dish and moulded to the PDMS at $150{ }^{\circ} \mathrm{C}$ for $1 \mathrm{~h}$ between two glass slides pressed together using office clips, using a Teflon sheet to ensure release of the polystyrene from the glass slide. Excess polystyrene was cut off to leave discs with similar dimensions to the original ceramic discs.

\subsection{Cell culture}

hMSCs were isolated from bone marrow aspirates obtained from donors who had given written informed consent. After isolation, hMSCs were expanded in proliferation medium, which consisted of basic medium ( $\alpha$-MEM (Life Technologies, Bleiswijk, the Netherlands), $10 \%$ $\mathrm{v} / \mathrm{v}$ foetal bovine serum, $0.2 \mathrm{mM}$ ascorbic acid (Life Technologies), $2 \mathrm{mM}$ L-glutamine (Life Technologies), $100 \mathrm{U} / \mathrm{mL}$ penicillin (Gibco, Landsmeer, the Netherlands) and $100 \mathrm{mg} / \mathrm{mL}$ streptomycin (Gibco), supplemented with $1 \mathrm{ng} / \mathrm{mL}$ basic fibroblast growth factor (bFGF) (Instruchemie, Delfzijl, the Netherlands). During culture, the cells were incubated at $37^{\circ} \mathrm{C}$ in a humidified atmosphere with $5 \% \mathrm{CO}_{2}$ and medium was refreshed every 3-4 days.

For RT-qPCR analysis, hMSCs were cultured in either basic medium or osteogenic medium (basic medium supplemented with $1 \mu \mathrm{M}$ dexamethasone). For Western blot, immunohistochemistry and nano LCMS analyses, cells were cultured in osteogenic medium. $2 \times 10^{5} \mathrm{hMSCs}$ were seeded onto either three ceramic particles or a single $63.5 \mathrm{~mm}^{2}$ ceramic or polystyrene disc, and cultured for $8 \mathrm{~h}, 48 \mathrm{~h}$ or $7 \mathrm{~d}$ as detailed in the results section. Each experiment was repeated at least twice and included a minimum of 3 replicates.

For transfection experiments, $1 \times 10^{5} \mathrm{hMSC}$ were seeded on three TCP ceramic particles and cultured in osteogenic medium for $4 \mathrm{~h}$. After $4 \mathrm{~h}$, cells were infected with viral particles containing either short hairpin RNA (shRNA) constructs targeting ENPP1 or scramble shRNA as a control, and cultured for a further $7 \mathrm{~d}$.

\subsection{Full proteome analysis by nano liquid chromatography - mass spectrometry ( $\mathrm{nLC}-\mathrm{MS}$ )}

Samples were trypsinised according to standard procedure. For each sample, $20 \mu \mathrm{L}$ of trypsinised cells was added to $20 \mu \mathrm{L}$ of $0.1 \%$ Rapigest (Waters Chromatography, Etten-Leur, the Netherlands) in $100 \mathrm{mM}$ triethylammonium bicarbonate (TEAB) buffer with a pH between 7.5 and 8. Samples were sonicated for $2 \mathrm{~min}$ using an ultrasonic cell disruptor at $70 \%$ power, then heated to $95^{\circ} \mathrm{C}$ for $5 \mathrm{~min}$. Samples were then reduced with DTT (dithiothreitol, $1 \mu \mathrm{L}$ of a $100 \mathrm{mM}$ solution, $30 \mathrm{~min}$, $60{ }^{\circ} \mathrm{C}$ ), cooled, and alkylated with $1 \mu \mathrm{L}$ of $300 \mathrm{mM}$ iodoacetamide (IAA) in the dark for $30 \mathrm{~min}$, before being incubated overnight at $37^{\circ} \mathrm{C}$ with $2 \mu \mathrm{L}$ of a $50 \mathrm{ng} / \mathrm{mL}$ trypsin solution. The reaction was then quenched and RapiGest hydrolysed by the addition of $0.5 \mu \mathrm{L} 25 \%$ trifluoroacetic acid (TFA). The $\mathrm{pH}$ of the solution was adjusted to 2 , and samples centrifuged at 20,800 $\mathrm{x} g$ for $20 \mathrm{~min}$.

Mass spectrometry measurements were performed on an Ultimate 3000 nanoLC system (Dionex, Germering, Germany) coupled to a hybrid linear ion trap/Orbitrap mass spectrometer (LTQ Orbitrap XL, Thermo Fisher Scientific, Bremen, Germany). $1 \mu \mathrm{L}$ of digest was loaded onto a C18 trap column (PepMap C18, $300 \mu \mathrm{m}$ ID x $5 \mathrm{~mm}$ length, $5 \mu \mathrm{m}$ particle size, $100 \AA$ pore size; Dionex) and desalted for $10 \mathrm{~min}$ with $20 \mu \mathrm{L} / \mathrm{min} 0.1 \%$ TFA. The trap column was then switched into line with the analytical column (PepMap C18, $75 \mu \mathrm{m}$ ID x $150 \mathrm{~mm}$ length, $3 \mu \mathrm{m}$ particle size, $100 \AA$ pore size; Dionex). Peptides were eluted with a flow rate of $300 \mathrm{~nL} / \mathrm{min}$ and a binary gradient of $0-25 \%$ solvent $\mathrm{B}$ over $120 \mathrm{~min}$, followed by $25-50 \%$ solvent B over $60 \mathrm{~min}$, where solvent A was $2 \%$ acetonitrile and $0.1 \%$ formic acid in water, and solvent B was $80 \%$ acetonitrile and $0.08 \%$ formic acid in water. A data-dependent acquisition method was used, with an initial high-resolution survey scan from $\mathrm{m} / \mathrm{z} 400$ to 1800 with the value of the automatic gain control (AGC) set to 106 , resolution of 30,000 at $\mathrm{m} / z 400$, and lock mass set to $445.120,025 \mathrm{u}$ (protonated $\left.\left.\left(\mathrm{Si}\left(\mathrm{CH}_{3}\right)_{2} \mathrm{O}\right)\right)_{6}\right)$. Based on this survey, the 5 most intense ions were consecutively isolated (AGC target set to 104) and fragmented by collision-activated dissociation applying 35\% normalised collision energy in the linear ion trap. After precursors were selected for MS/MS, they were excluded from further MS/MS spectra for $3 \mathrm{~min}$.

Raw data were preprocessed using the Progenesis 4.0 software package (Nonlinear Dynamics, Newcastle-upon-Tyne, UK). Peptides were identified and assigned to proteins by exporting features using Bioworks 3.2 (Thermo Fisher, Germany). The resulting file was submitted to Mascot v2 (Matrix Science, London, UK) for identification using the UniProt Homo sapiens database (release 2013_07, containing 20,265 sequences). Only ions with a charge between +2 and +8 were considered, and only proteins with at least two unique peptides (Mascot ions score $>25$, corresponding to a peptide probability cutoff of 0.01 ) were accepted as identifications. Carbamidomethylation of cysteine was set as fixed, and oxidation of methionine as variable, allowing for a maximum of 2 missed cleavages. Mass tolerance was set to $10 \mathrm{ppm}$ for precursor ions and 0.2 Da for fragment ions. Mascot search results were imported back into Progenesis to link identified peptides to their detected abundances, which were normalised to the total ion current to compensate for experimental variations.

Scaffold (Proteome Software Inc., Portland, OR, USA) was also used to validate protein identifications derived from MS/MS results. This software verified peptide identifications using the X!Tandem database searching program [34,35]. Peptide identifications were probabilistically validated using PeptideProphet [36] and corresponding protein probabilities derived using ProteinProphet $[37,38]$.

\subsection{Real-time quantitative PCR analysis}

Total RNA was isolated from hMSCs using a NucleoSpin RNA II kit (Macherey-Nagel, Düren, Germany) according to the manufacturer's instructions, and its concentration measured using a nanoDrop spectrophotometer (Thermo Fisher). Reverse transcription of cDNA from 370 ng mRNA was performed using an iScript cDNA Synthesis Kit (BioRad, Hercules, CA, USA). Gene expression was normalised to GAPDH, and relative changes in expression were calculated using the $\Delta \mathrm{CT}$

Table 1

Sequences of primers used for RT-qPCR.

\begin{tabular}{ll}
\hline Gene Target & Primer Sequence \\
\hline ENPP1 & (F) $5^{\prime}$ - CAGCGACCTTTGCAACTTTT (R) 5' - CCAAGGACCCCAACACCTA \\
$B M P 2$ & (F) 5' - ACTACCAGAAACGAGTGGGAA (R) 5' - GCATCTGTTCTCGGAAAACCT \\
$O P N$ & (F) 5' - CTCCATTGACTCGAACGACTC (R) 5' - CAGGTCTGCGAAACTTCTTAGAT \\
$A L P$ & (F) 5' - ACAAGCACTCCCACTTCATC (R) 5' - TTCAGCTCGTACTGCATGTC \\
GAPDH & (F) 5 ' - CGCTCTCTGCTCCTCCTGTT (R) 5' - CCATGGTGTCTGAGCGATGT
\end{tabular}


method. Primer sequences used are summarised in Table 1.

\subsection{Western blot analysis}

Cells cultured on biomaterials were lysed directly from the cellmaterial constructs using the Ripa lysis buffer system (Santa Cruz Biotechnology, Dallas, TX, USA). Protein concentration was determined using a bicinchoninic acid (BCA) assay kit (Pierce, Rockford, IL, USA) according to the manufacturer's instructions. Equivalent amounts of protein were separated by SDS-PAGE on a $15 \%$ gradient precast polyacrylamide gel (Biorad; $1.5 \mathrm{~h}, 200 \mathrm{~V}, 100 \mathrm{~mA}$ ), then transferred onto a mini format $0.2 \mu \mathrm{m}$ PVDF membrane (Bio-Rad) using a Trans-Blot Turbo system (Bio-Rad) at $25 \mathrm{~V}$ and $1.3 \mathrm{~A}$ for $7 \mathrm{~min}$. The membrane was blocked using 5\% non-fat dried milk in Tris-buffered saline (TBS) for $1 \mathrm{~h}$, before incubation with primary antibodies for $16 \mathrm{~h}$ at $4{ }^{\circ} \mathrm{C}$, and with secondary antibodies (horseradish peroxidase-conjugated goat antirabbit or anti-mouse, Bio-Rad) for $1 \mathrm{~h}$ at room temperature. The membrane was incubated with chemiluminescent detection reagent (Pierce) for $1 \mathrm{~min}$, then developed with the FluorChem $M$ system (ProteinSimple, San Jose, CA, USA). The primary antibodies used were rabbit anti-human PC-1 polyclonal (Santa Cruz), rabbit anti-human BMP2 polyclonal (Thermo Fisher) and mouse anti-human GAPDH polyclonal (Santa Cruz).

\subsection{Immunofluorescence analysis}

After 7d of culture, the cell-ceramic constructs were fixed with $4 \%$ $\mathrm{w} / \mathrm{v}$ paraformaldehyde for $15 \mathrm{~min}$ at room temperature, then washed twice with PBS. Samples were then decalcified in $4 \%$ formic acid for 2 $3 \mathrm{~d}$, dehydrated using an ethanol series, embedded in paraffin, and cut into $5 \mu \mathrm{m}$ sections. Sections were deparaffinised in xylene and rehydrated using an ethanol series, before being incubated overnight at room temperature with rabbit anti-human PC-1 primary antibody (Santa Cruz) diluted 1:100 in PBS with 1\% BSA. Alexa Fluor 488-conjugated donkey anti-rabbit IgG (Fisher) was used as the secondary antibody, and nuclei stained with DAPI (Sigma). Sections were mounted using standard techniques and imaged using Nikon Eclipse E600 and Nikon confocal A1/super resolution N-STORM microscopes (Nikon Europe, Amsterdam, the Netherlands; BioNanolab, University of Twente, Enschede, the Netherlands). DAPI (excitation at $360 \mathrm{~nm}$, emission at $460 \mathrm{~nm}$, blue) and Alexa Fluor 488 (excitation at $495 \mathrm{~nm}$, emission at $519 \mathrm{~nm}$, green) signals were collected and merged into single images.

\subsection{Laser capture microdissection}

Samples were processed for immunofluorescence as detailed above, except that polyethylene naphthalene (PEN) membrane slides were used instead of conventional glass histology slides. Laser capture microdissection was performed as described previously [39]. Briefly, slides were washed 3 times with PBS, air-dried and placed on a PALM Microbeam IV laser microdissection system (Zeiss, Jena, Germany), with AdhesiveCap 500 (Zeiss) used to collect cut tissues. Both tissues containing hMSCs in direct contact with the ceramic surface and tissues containing cells from the ceramic pore, which were not in direct contact with the surface, were selected. Samples were dissolved in $20 \mu \mathrm{L} \mathrm{di-}$ gestion buffer containing 0.1\% RapiGest (Waters) and $100 \mathrm{mM}$ TEAB, and stored at $-80{ }^{\circ} \mathrm{C}$ until they were analysed using nLC-MS as described above.

\subsection{ENPP1 silencing by shRNA}

The RNAi Consortium (TRC) human lentiviral shRNA libraries with clone ID TRC TRCN0000002537 were obtained from Dharmacon (Lafayette, CO, USA). Control constructs were scrambled with sh sequence CCTAAGGTTAAGTCGCCCTCG in plko.1-puromycin. Lentivirus particles were produced according to a literature protocol [40]. Briefly, HEK293FT cells were transfected with the plko.1 construct using the packaging plasmids pcmv-VSV-G and psPax2 and the transfection reagent PPei (Polysciences, Warrington, PA, USA). Virus particles were collected $48 \mathrm{~h}$ post-transfection, filtered through a $0.45 \mu \mathrm{m}$ membrane and snap-frozen until they were used in functional studies.

\subsection{Elemental analysis of cell culture media by ICP-MS}

Concentrations of calcium and phosphorus in cell culture medium were quantified by ICP-MS (iCaP Q, Thermo Scientific). $1 \mathrm{~mL}$ of medium was collected from each set of cell culture conditions (uncoated and collagen-coated HA and TCP), and from an empty well as control, before medium refreshment at $2 \mathrm{~d}, 5 \mathrm{~d}$ and $7 \mathrm{~d}$ of culture, and stored at $-30^{\circ} \mathrm{C}$ until analysis. Samples were thawed, vortexed for $30 \mathrm{~s}$, and diluted 1:50 in $1 \% \mathrm{HNO}_{3}$ with the addition of $20 \mathrm{ppb}$ scandium as internal standard. Quantification was performed in KED mode with $\mathrm{He}$ as collision gas. A standard curve of 100, 200, 500 and $5000 \mathrm{ppb} P$ and Ca was prepared in the same matrix medium as the samples, and fresh cell culture medium from the same batch was used as the blank. Data were expressed relative to concentrations in fresh cell culture medium.

\subsection{Statistical analysis}

Data were analysed using GraphPad Prism 6.0 as detailed in the Results section. One-way ANOVA with Tukey's post-hoc test was used for all cell culture experiments with the exception of ENPP1 knockdown. Two-way ANOVA with Tukey's post-hoc test was used for ICP-MS experiments, Student's T-test for ENPP1 knockdown experiments, and Fisher's exact test for the comparison of proteomics data after microdissection. For proteomics data, two-way ANOVA with Bonferroni's post-hoc test was applied. Differences were considered to be significant if the $\mathrm{p}$-value was $<0.05$.

\section{Results}

3.1. Identification of proteins expressed by hMSCs on CaP ceramics with different osteoinductive potential using proteomics

hMSCs from one donor were cultured on two osteoinductive ceramics (TCP and BCP1150) and two non-osteoinductive ceramics (HA and $\mathrm{BCP} 1300)$ for $8 \mathrm{~h}, 48 \mathrm{~h}$ and $7 \mathrm{~d}$ in osteogenic medium, followed by a full proteomic analysis using nLC-MS.

Fig. 1 shows the top 50 proteins overexpressed after $7 \mathrm{~d}$ in hMSCs cultured on the osteoinductive ceramics (TCP and BCP1150) compared to hMSCs cultured on the non-osteoinductive ceramics (HA and BCP1300). It was also shown that most of these proteins were overexpressed in hMSCs on all CaP ceramics (both osteoinductive and nonosteoinductive) compared to control experiments where hMSCs were cultured on 2D tissue culture polystyrene plates. This suggests a role for either the 3D environment or the presence of non-specific CaP in their regulation.

The Gene Ontology term enrichment analysis of the data for biological process, cellular component, and molecular function, as well as the pathway analysis were performed and will be published separately.

In the top-50 list, PC-1, which is known to be involved in the regulation of tissue mineralisation [41] and osteogenic differentiation [42] was identified as a protein of interest. Another interesting protein identified was Matrix Gla-Protein (MGP) which has a role in vascular calcification [43] and endochondral ossification [44]. The potential role of MGP in osteoinduction will be investigated separately.

\subsection{Validation of overexpression of ENPP1 $m R N A$ and PC-1 on} osteoinductive ceramics

To measure the change in expression of ENPP1 and PC-1 on 


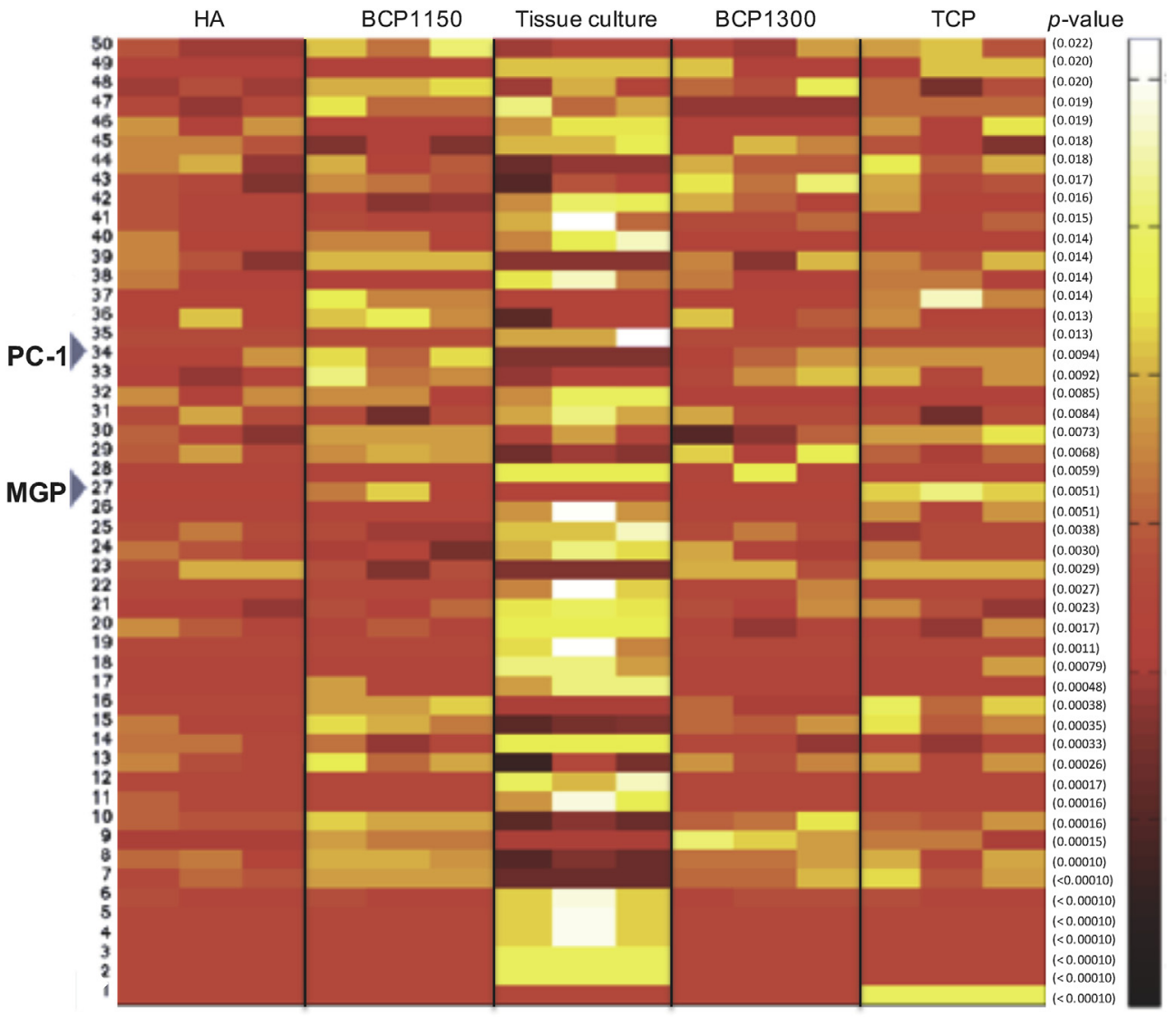

Fig. 1. An overview of the 50 proteins identified as having the largest difference in abundance between hMSCs cultured on osteoinductive TCP and ВCP1150 and those cultured on non-osteoinductive $\mathrm{HA}$ and BCP1300 after $7 d$ culture in osteogenic medium. Proteins are sorted from 1 (most significant) to 50 (least significant) based on the statistical significance of differential expression ( $n=3$, ANOVA with Bonferroni post-hoc test). Each block represents a biological replicate. MGP $=$ Matrix Gla Protein; PC1 = Plasma cell glycoprotein 1 . The complete list of proteins is given in the Supplementary Information.

osteoinductive compared to non-osteoinductive CaP ceramics, hMSCs were cultured on the two osteoinductive (TCP and BCP1150) and the two non-osteoinductive (HA and BCP1300) ceramics in osteogenic medium for $8 \mathrm{~h}, 48 \mathrm{~h}$ and $7 \mathrm{~d}$. Expression levels of ENPP1 and PC-1 were measured by RT-qPCR and Western immunoblotting respectively (Fig. 2).

Before $7 \mathrm{~d}$, expression levels of PC-1 were the same across the four ceramics. At $48 \mathrm{~h}$, the level of ENPP1 mRNA was increased on TCP, but not on BCP1150, compared to the non-osteoinductive ceramics. However, by 7d, expression levels of both ENPP1 and PC-1 were higher on osteoinductive than on non-osteoinductive ceramics. This effect was also observed when cells were cultured in basic (non-osteogenic) medium (Fig. S1), so can be considered to be independent of the cell culture medium used.

In addition, mRNA levels of the well-established osteogenic markers $B M P 2, O P N$ and $A L P$ were measured by RT-qPCR after $7 \mathrm{~d}$ to determine whether these also showed differential expression on the four ceramics (Fig. S2). These measurements showed a significant upregulation of OPN on both TCP and BCP1150, and of BMP2 on TCP, compared to the non-osteoinductive ceramics. This is in accordance with previous experiments [4]. In contrast, $A L P$ showed similar expression levels across all four ceramics, but this is again in accordance with previous studies which have shown that $A L P$ is not upregulated in the presence of osteoinductive ceramics [45].

In general, these results have shown that, like other known markers of osteogenic differentiation, ENPP1 and PC-1 are upregulated on osteoinductive compared to non-osteoinductive ceramics.

\subsection{Spatial distribution of hMSCs expressing PC-1}

In the previous section, we showed that ENPP1 and PC-1 are upregulated in hMSCs cultured on osteoinductive ceramics relative to those cultured on non-osteoinductive ceramics. Cells cultured on 3-D materials such as the ceramics used in this study often exhibit phenotypic heterogeneity depending on their position within the 3-D construct. Therefore, we set out to determine if the increased PC-1 expression levels were restricted to a spatially distinct subpopulation of cells on the osteoinductive ceramics. After $7 \mathrm{~d}$ of culture in osteogenic medium, samples were decalcified and immunohistochemically stained for PC-1 (Fig. 3). Cells expressing PC-1 were almost absent on the nonosteoinductive ceramics, as expected from the Western blot results. In contrast, on both osteoinductive ceramics, $\mathrm{PC}-1^{+}$cells were exclusively observed in direct contact with the surface of the osteoinductive ceramic. Cells within the pores of the ceramic, but not in direct contact with its surface, did not express PC-1 (see Fig. 3).

To further confirm these observations, we isolated the PC- $1^{+}$cells by laser microdissection and obtained a proteomic profile by LC-MS/MS analysis. This was compared with a similar profile of cells isolated from the pores of the ceramic. These results confirmed the presence of two distinct subpopulations of cells on osteoinductive ceramics. PC-1 expression is restricted to those cells in direct contact with the surface. 77 other proteins were also found to be expressed exclusively in this subpopulation, while 11 were found to be expressed exclusively in the subpopulation of cells in the ceramic pores with no contact with the surface (Table S2). In addition, 41 proteins were found to have different expression levels between the two subpopulations (Table S3).

Overall, these results confirmed that only the subpopulation of hMSCs in direct contact with the surface of an osteoinductive ceramic express PC-1, and that these cells have a different proteomic profile from the cells not in contact with the surface.

\subsection{Effect of surface modification with collagen on the expression of ENPP1}

Having determined that direct contact with the ceramic surface affects the expression of PC-1, we next investigated the effect of the surface chemistry of the ceramic on this relationship. HA and TCP 


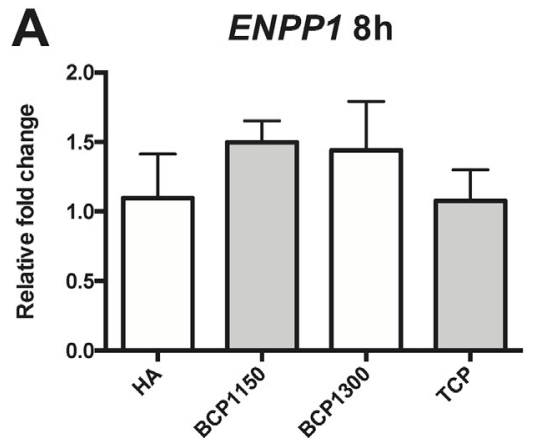

B

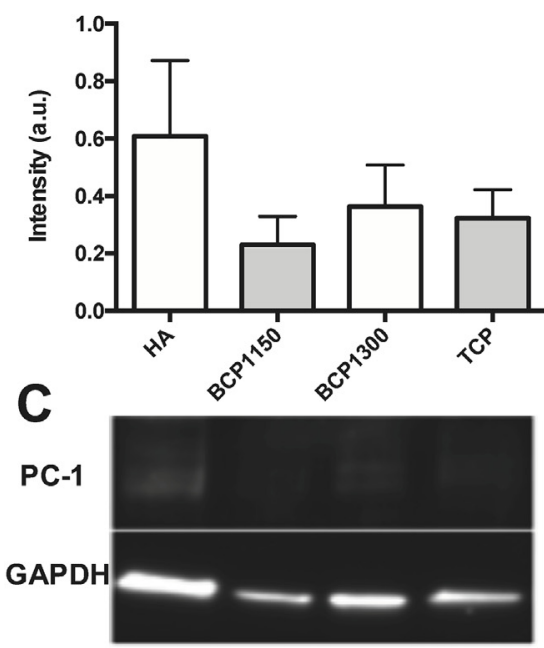

ENPP1 48h

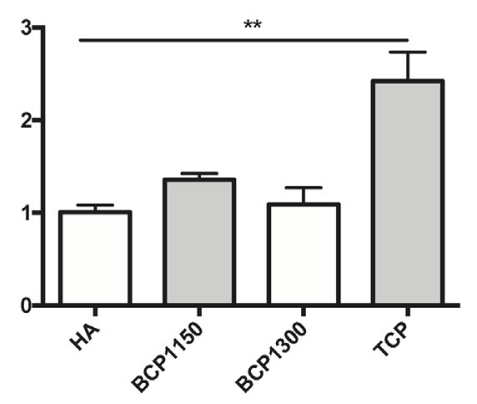

$\mathrm{PC}-1$ 48h
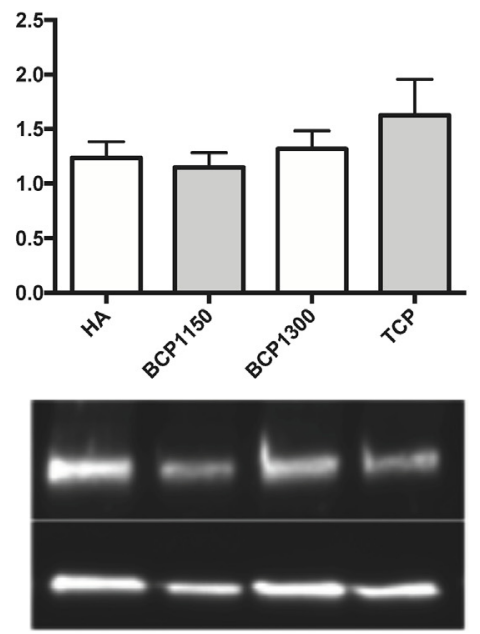

ENPP1 7d

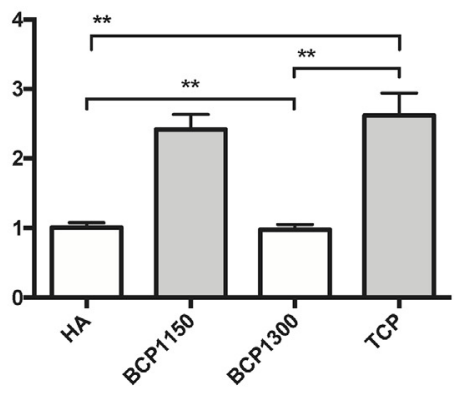

PC-1 7d

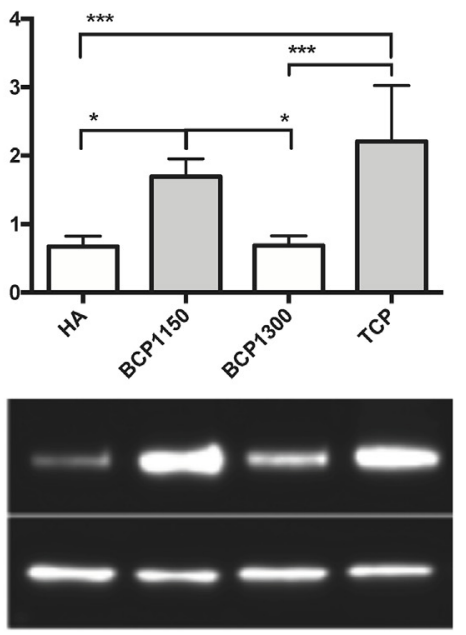

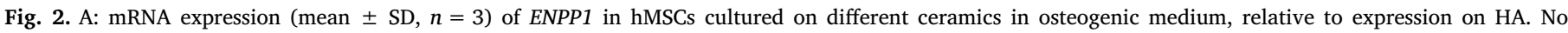

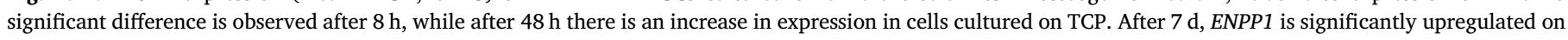

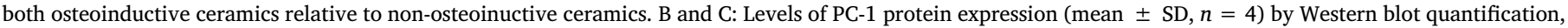

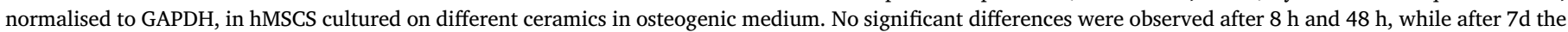

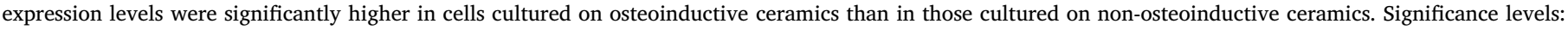
${ }^{*} p<0.05,{ }^{* * p}<0.01,{ }^{* *} p<0.001$ (One-way ANOVA with Tukey's post-hoc test).

ceramic discs were dip-coated with collagen in order to 'cover' the CaP surface chemistry and replace it with collagen surface chemistry. Scanning electron microscopy (SEM) imaging of the ceramic discs before and after the coating process suggested that a very thin collagen layer was deposited on the ceramic surface (Fig. S3). Further optical profilometry analysis showed a small to non-existent difference in arithmetic mean height (Sa) between uncoated and collagen-coated HA and TCP ceramics, whereas both ceramics exhibited a decrease in arithmetic mean peak curvature (Spc) (Table S4). Smaller values of Spc indicate that the surface peaks which form points of contact with other objects have more rounded shapes, which coincides with a somewhat smoother appearance of the coated surface on SEM images and suggests that the collagen coating deposited on the surface was very thin.

In order to investigate the effect of the collagen coating on ion exchange between the ceramic and the medium, concentrations of calcium and phosphorus in the medium were quantified by ICP-MS after $2 \mathrm{~d}, 5 \mathrm{~d}$ and $7 \mathrm{~d}$ of cell culture (Fig. 4). While a difference in ion concentration was apparent between HA and TCP (as can be expected given their different structure and composition), no significant effect of the coating on calcium and phosphate concentration in the medium was observed at any point. Profilometry analysis of the ceramic discs after immersion for $7 \mathrm{~d}$ in cell culture medium showed that the arithmetic mean height (Sa) of HA discs showed a small increase, whereas that of TCP, with more pronounced surface dynamics in terms of ion exchange, showed a further small decrease (Table S4). This suggests that the coating was not stable over the 7 day period.
Therefore, while the coated ceramics initially presented a different surface chemistry to the hMSCs, their ability to exchange calcium and phosphate ions with their surroundings was unaffected because the coating was very thin and unstable.

hMSCs were cultured for 7 days in osteogenic medium on the coated and uncoated ceramics, and the mRNA expression of ENPP1, BMP2, $O P N$ and $A L P$ was analysed (Fig. 5). ALP expression levels increased significantly on collagen-coated HA relative to uncoated HA. On the other hand, ALP levels on coated TCP were reduced below the limit of detection.

Levels of ENPP1 and the other two osteogenic markers, all of which have previously shown upregulation on osteoinductive ceramics, did not differ significantly between coated and uncoated HA. On the TCP discs, a significantly lower level of $O P N$ expression was observed on the coated ceramic, while no significant difference was seen in the levels of ENPP1 and BMP2 between coated and uncoated ceramic.

Overall, these results suggest that covering the surface chemistry of an osteoinductive ceramic with collagen has limited, if any, effects on the response of cells to the ceramic.

\subsection{The effect of surface microstructure on the expression of ENPP1}

Surface microstructure is known to be important in determining whether a ceramic is osteoinductive. Osteoinductive BCP1150 and nonosteoinductive BCP1300 differ only in their microstructure and not in their chemistry $[3,18,19]$. Non-osteoinductive HA and osteoinductive 


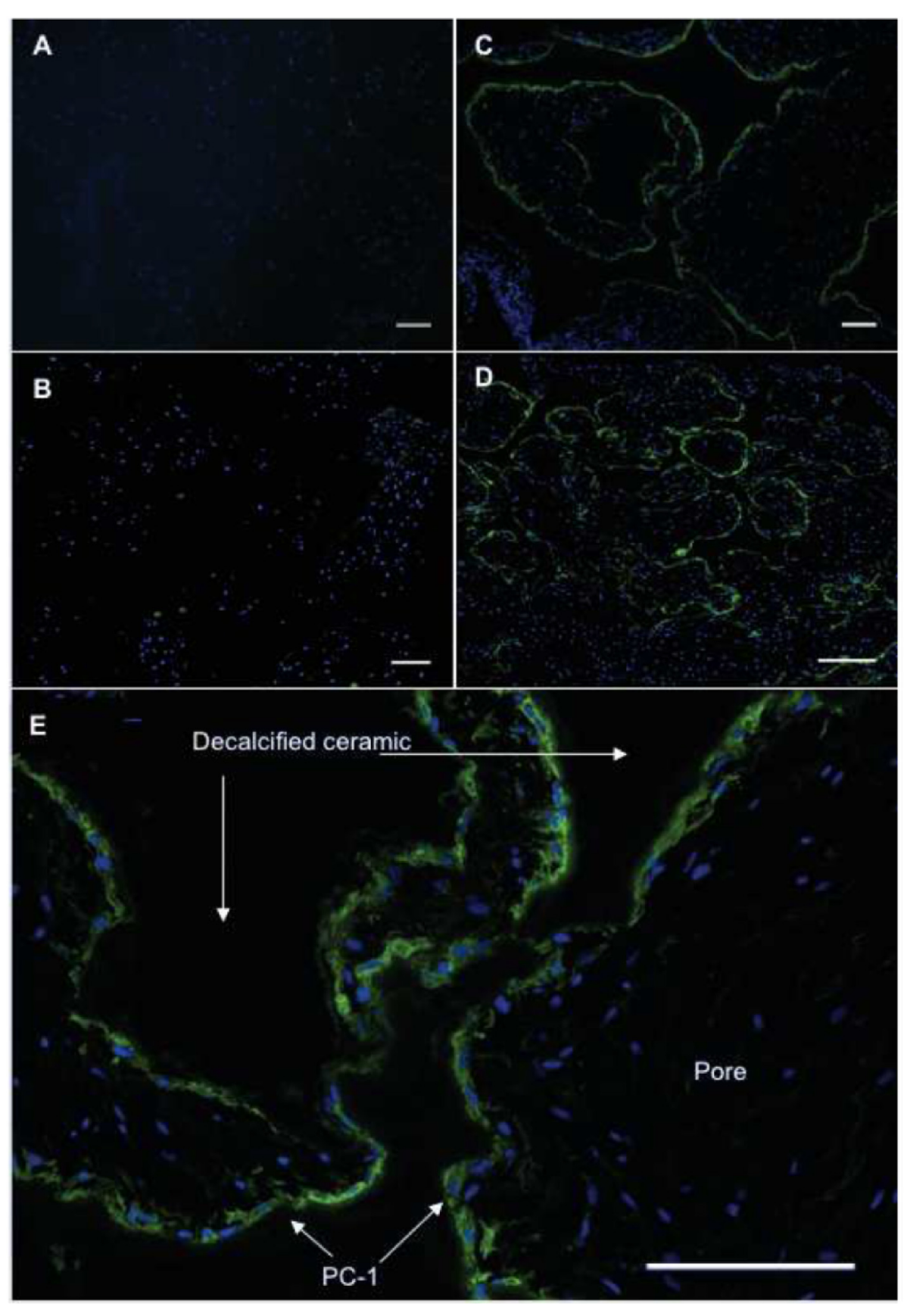

Fig. 3. Immunohistochemical staining of PC-1 (green) on decalcified histological sections of hMSCs cultured on HA (A), BCP1300 (B), TCP (C) and BCP1150 (D). $P C-1^{+}$staining is observed only in cells in direct contact with osteoinductive materials, not in cells distant from the surface or cultured on non-osteoinductive materials. Image $\mathrm{E}$ is an enlargement of image C. Nuclei are stained in blue. All scale bars are $500 \mu \mathrm{m}$. Images are representative results from at least three independent experiments using hMSCs from two different donors. (For interpretation of the references to colour in this figure legend, the reader is referred to the Web version of this article.)
$\mathrm{Ca}$

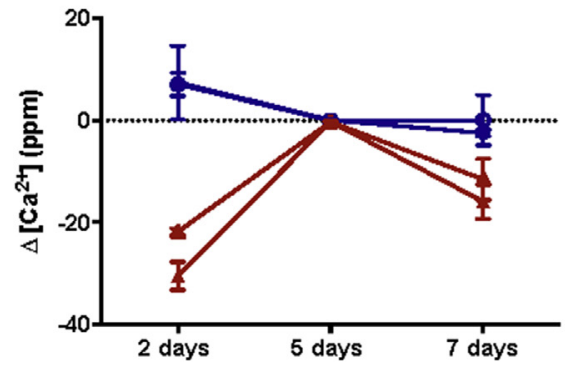

$\mathbf{P}$

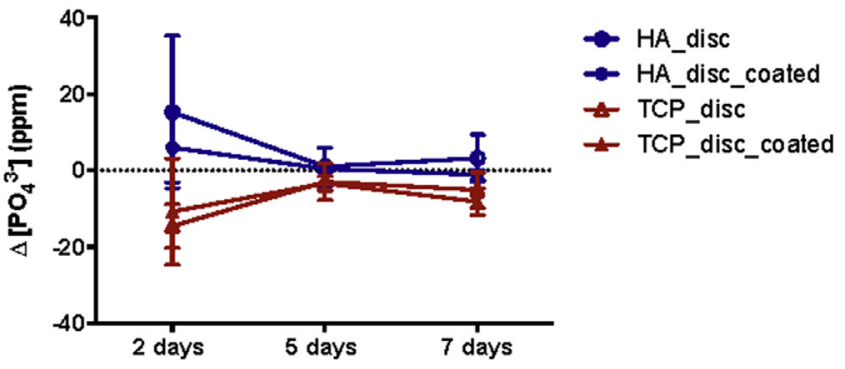

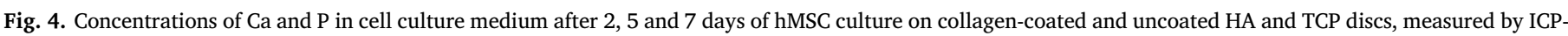

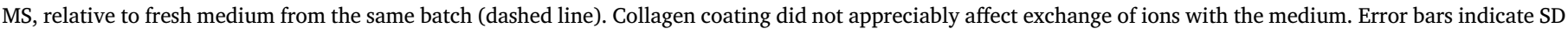
( $n=3$, two-way ANOVA with Tukey's post-hoc test). 

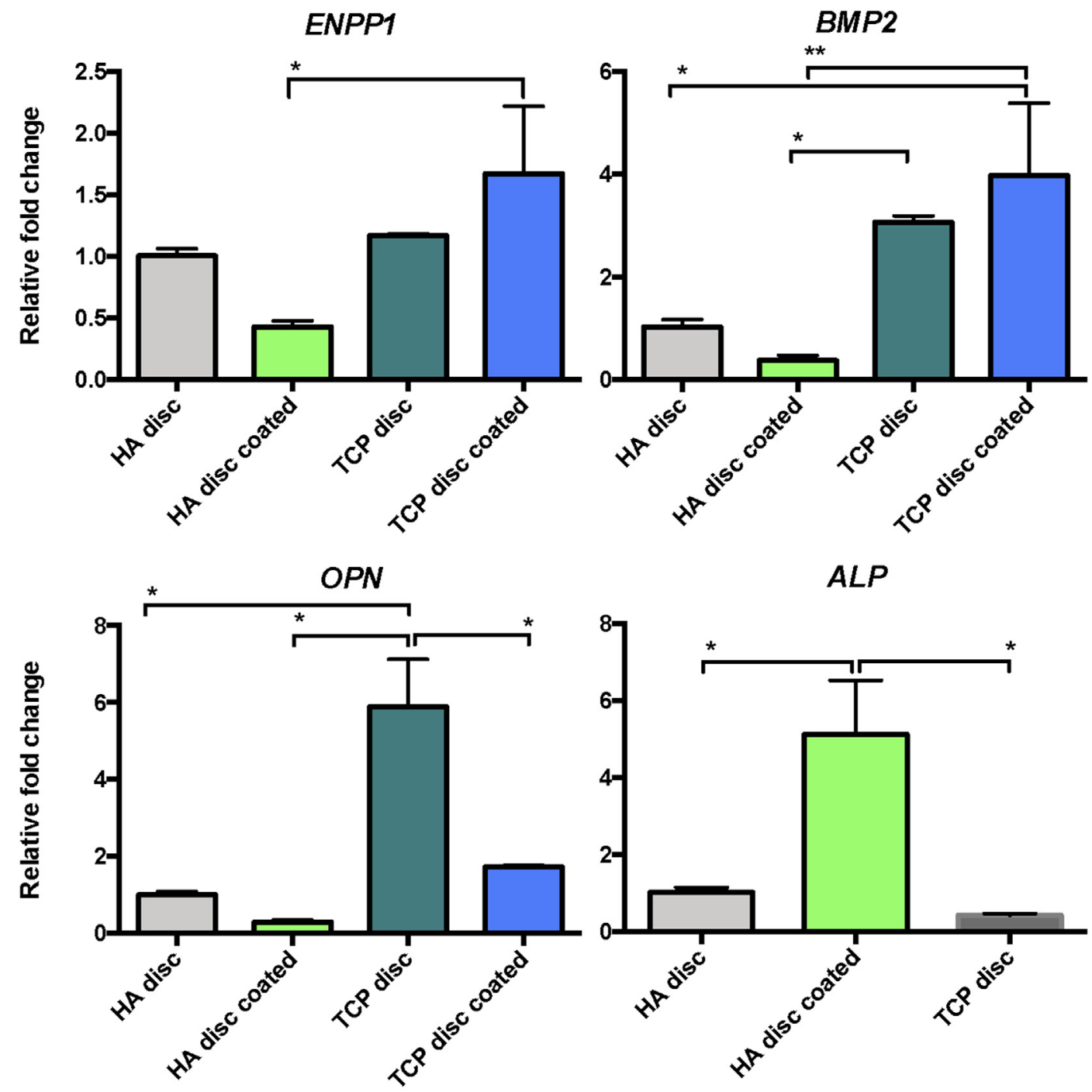

Fig. 5. mRNA expression (mean $\pm \mathrm{SD}, n=3$ ) of ENPP1, BMP2, OPN and ALP in hMSCs cultured on HA and TCP discs, either uncoated or coated with a collagen layer, after $7 \mathrm{~d}$ culture in osteogenic medium. Values are relative to uncoated HA. On non-osteoinductive HA, collagen coating of the ceramic significantly increased $A L P$ expression, while there was a non-significant trend towards a decrease in the other three osteogenic markers. On osteoinductive TCP, collagen coating resulted in a significantly lower level of $O P N$ expression, but no significant change in ENPP1 and BMP2 expression. ALP mRNA could not be detected in cells cultured on coated TCP. All data are normalised against GAPDH. ${ }^{*} p>0.05,{ }^{* *} p>0.01$ (One-way ANOVA, Tukey's post-hoc test).

TCP are chemically different and also differ in their surface structure [30]. Therefore, we aimed to decouple surface structure from surface chemistry and investigate the role of structure alone on the expression of ENPP1, BMP2, OPN and ALP.

The surface structures of HA and TCP ceramic discs were replicated effectively and with high fidelity in a polystyrene film using previously described micromoulding techniques [31,33]. hMSCs were cultured on these replicas and on the original ceramic discs, as well as on flat polystyrene as a control, for 7 days in osteogenic medium. With the exception of $A L P$, which was upregulated on the polystyrene replica of TCP, osteogenic markers were not significantly upregulated on the polystyrene replicas compared to flat polystyrene controls (Fig. 6).

These results suggest that surface structure in the absence of $\mathrm{CaP}$ chemistry is not sufficient for osteogenic differentiation of hMSCs or for the expression of ENPP1, BMP2 and OPN.

\subsection{Correlation between ENPP1 and BMP2 expression}

To investigate the correlation between ENPP1/PC-1 expression and other markers of osteogenic differentiation, the expression of ENPP1 in hMSCs was suppressed using shRNA. hMSCs with shRNA-targeted
ENPP1 knockdown were cultured on osteoinductive TCP particles in osteogenic medium for 7 days. The effectiveness of the knockdown in reducing ENPP1 expression and PC-1 production was validated by RTqPCR and Western blotting (Fig. 7).

In cells with suppressed ENPP1 expression, BMP2 mRNA expression significantly increased, while BMP2 protein production also showed an increase. In contrast, levels of $O P N$ and $A L P$ mRNA significantly decreased. These data suggest that targeting ENPP1 for knockdown in hMSCs cultured on osteoinductive ceramics enhances BMP2 expression at both mRNA and protein levels, while reducing $A L P$ and $O P N$ expression.

\section{Discussion}

CaP-based ceramics have been used in the treatment of large bone defects for the last five decades [21]. However, they have still not completely replaced natural bone grafts such as autografts. Such comprehensive replacement has only been considered possible since it was demonstrated that some $\mathrm{CaP}$ ceramics, depending on their chemical and physical properties, have the ability to induce new bone formation even at heterotopic implantation sites [20]. For example, in one study an 
ENPP1
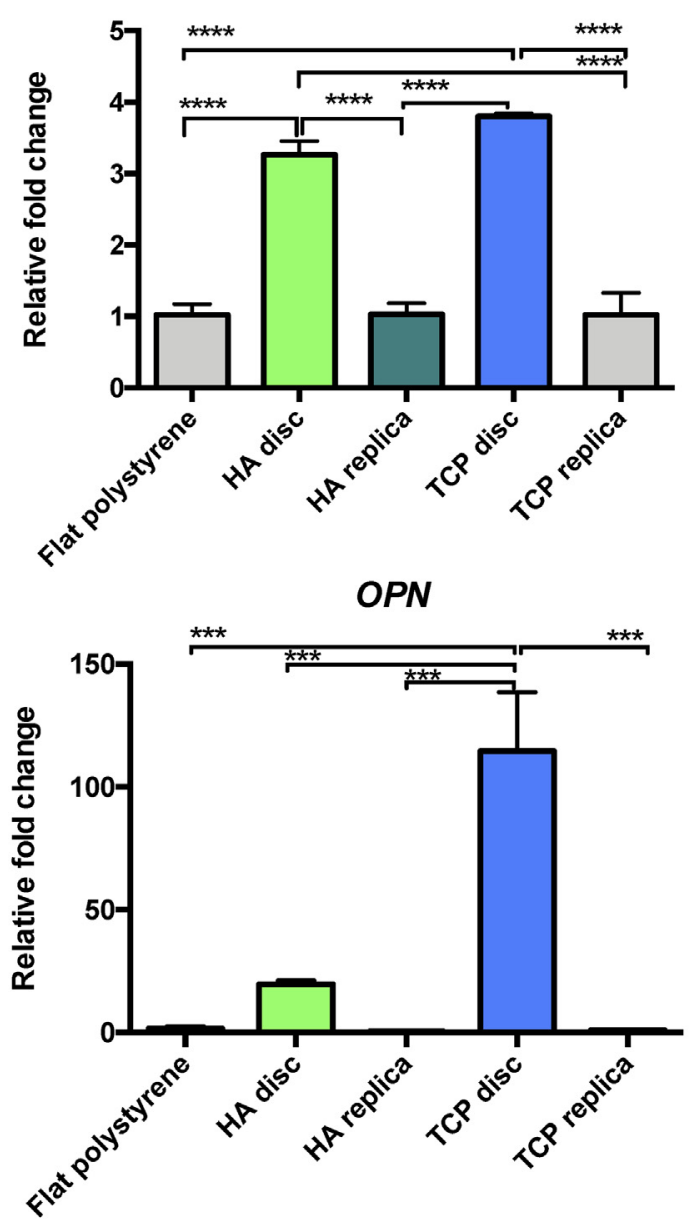

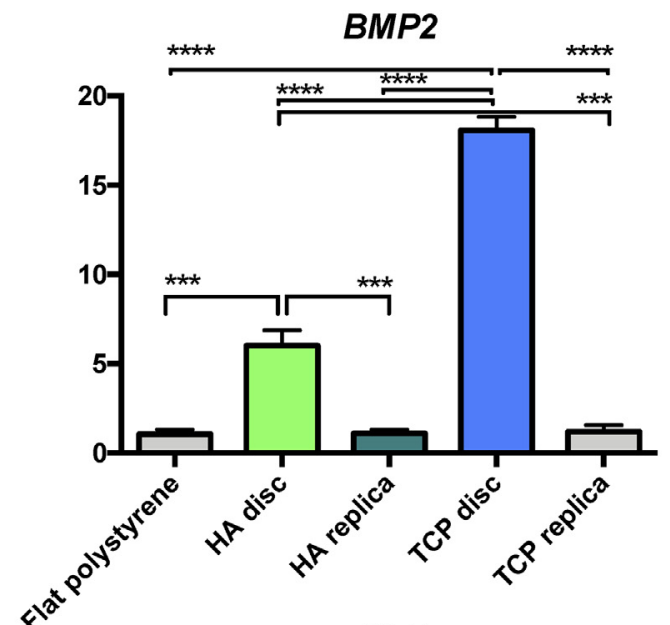

$A L P$

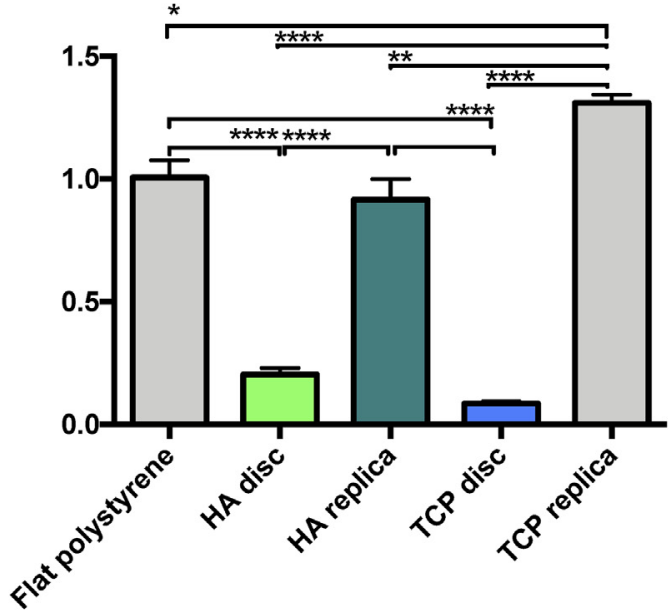

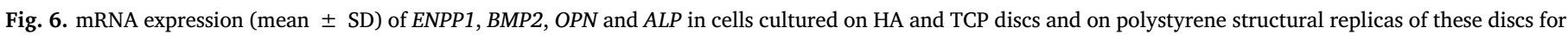

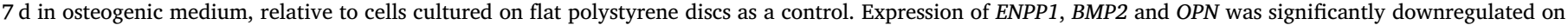

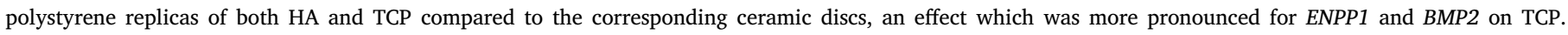

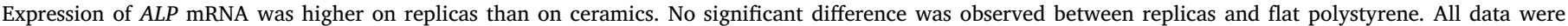
normalised to GAPDH mRNA. * $p<0.05,{ }^{* *} p<0.01,{ }^{* * *} p<0.001,{ }^{* * *} p<0.0001$ (one-way ANOVA, Tukey's post-hoc test).

osteoinductive TCP ceramic was shown both to induce heterotopic bone formation and to be as effective as autografted bone in regenerating a $17 \mathrm{~mm}$ iliac wing bone defect in sheep [30].

Despite this and several other successful examples of osteoinductive CaP ceramics [20], the development of these ceramics has not yet made the use of natural bone grafts obsolete. For instance, osteoinductive $\mathrm{CaP}$ ceramics are inherently brittle due to their porosity, and it has not yet been possible to improve their mechanical properties without compromising their bioactivity. In addition, the rate of new bone formation still needs to be better controlled so that it matches the degradation rate of the ceramic in vivo.

The research and development efforts needed to solve these problems would benefit from an improved understanding of the mechanism of osteoinduction. Knowledge of the role of individual material properties in determining whether, and to what extent, a CaP ceramic is osteoinductive would open the way towards rational design of these materials with improved properties. In an attempt to shed light on this mechanism, the starting point of this study was a full proteome analysis of clinically relevant hMSCs on a set of four CaP ceramics known to be osteoinductive or non-osteoinductive. The physical and chemical properties of these ceramics, their in vivo bone forming potential, and their effect on the expression of osteogenic markers at mRNA level, have already been described $[4,30,46,47]$.

The proteome analysis in the current study identified PC-1 as a protein of interest. Notably, none of the classical osteoblast markers such as BMP2, OPN, runt-related transcription factor 2 (RUNX2), ALP and bone gamma carboxyglutamate protein (BGLAP) were found to be differentially expressed on osteoinductive versus non-osteoinductive $\mathrm{CaP}$ ceramics. However, these markers were also not observed in an earlier proteomic study of osteoblasts cultured on tissue culture polystyrene [48]. That study attributed the lack of detection to low abundance of these proteins, potentially below the detection limit of the LCMS/MS device, which may also explain why they do not appear in the list of differentially expressed proteins in this proteomic analysis. The overexpression of ENPP1/PC-1 on osteoinductive relative to non-osteoinductive $\mathrm{CaP}$ ceramics was validated using RT-qPCR, Western blot analysis, and immunohistochemical staining.

The role of ENPP1 in regulation of tissue mineralisation is well established. Mice with a truncation mutation in the ENPP1 gene resulting in loss of function, also known as the "tiptoe walking" (ttw/ttw) mutation, exhibit symptoms of heterotopic tissue mineralisation including peri-articular and articular calcifications and progressive fusion of spinal ligaments [49]. A similar phenotype has been observed in mice where the ENPP1 gene has been knocked down [50]. In humans, mutations in the ENPP1 gene are linked to general arterial calcification of infancy (GACI), a disorder characterised by the calcification of arteries before birth or within the first few months of life [41,51].

PC-1 is the main enzyme involved in the generation of extracellular 

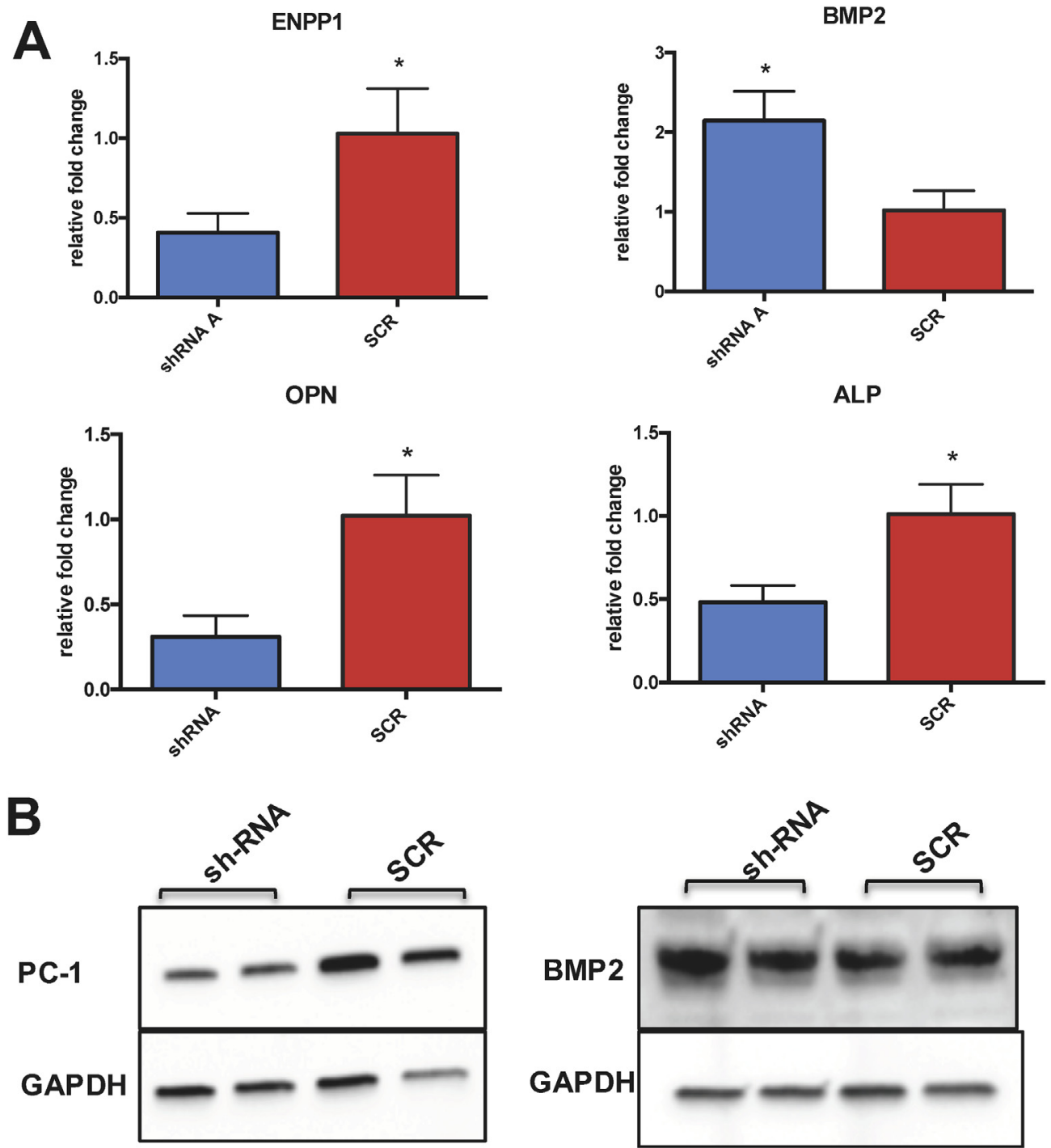

Fig. 7. A: Expression levels (mean $\pm \mathrm{SD}, n=3$ ) of ENPP1, BMP2, OPN and ALP in hMSCs with suppressed ENPP1 cultured for $7 \mathrm{~d}$ on TCP particles in osteogenic medium, relative to cells treated with a scrambled control shRNA (SCR). Data normalised to GAPDH. * $p<0.05$ (Unpaired Student's t-test) B: Western blots of PC-1 and BMP-2 in hMSCs with suppressed ENPP1 and hMSCs treated with a scrambled control shRNA, cultured $7 \mathrm{~d}$ on TCP particles in osteogenic medium. Suppression of $E N P P 1$ increased expression of BMP2 at gene and protein levels while significantly decreasing $O P N$ and $A L P$ expression.

PPi by mature osteoblasts and chondrocytes [52,53], which is important in the regulation of hard and soft tissue mineralisation [42]. As PPi inhibits HA precipitation, ENPP1 acts to negatively regulate mineralisation by producing PPi. However, PPi is also hydrolysed by TNAP to yield $\mathrm{Pi}$, which is a precursor to bone mineral. The interplay of the activities of PC-1, TNAP, Ank, PiT-1 and PHOSPHO1 regulates the $\mathrm{Pi} / \mathrm{PPi}$ ratio both inside and outside cells, preventing calcification of soft tissues by keeping the concentration of extracellular PPi high, while inducing bone mineralisation by hydrolysing PPi to Pi [54]. In addition, a recent study in mice has shown that ENPP1/PC-1 negatively regulates the hedgehog signalling pathway [29] which is also important in endochondral bone formation [55]. However, while the role of ENPP1 in natural bone formation has been extensively described, to our knowledge there is as yet no evidence of its role in the control of bone formation induced or supported by CaP ceramics.

In addition to ENPP1, this study showed that expression of the osteogenic markers BMP2 and OPN increased significantly on osteoinductive compared to non-osteoinductive CaP ceramics, a result that was in accordance with previous studies $[4,56]$. This effect was also observed when the cells were cultured in basic rather than osteogenic medium, suggesting that osteogenic differentiation is triggered by osteoinductive ceramic materials even in the absence of osteogenesisstimulating factors. In contrast to these three markers, the mRNA expression of $A L P$ was low and did not vary significantly between ceramics. This is again in accordance with the previous finding that the presence of $\mathrm{CaP}$ ceramics significantly decreases $A L P$ expression, especially in osteogenic medium [45].

Earlier studies on the interaction between these osteogenic markers have shown that $O P N$ expression is promoted by increased levels of PPi, which is generated by PC-1 [57]. OPN, in turn, suppresses the deposition of HA crystals, inhibiting calcification [58]. In contrast, ALP decreases levels of PPi, thereby antagonising this inhibitory effect of PC-1 on ectopic calcification [59]. Silencing ENPP1 expression in hMSCs resulted in the downregulation of both $O P N$ and $A L P$. It is expected that lower levels of PPi result in reduced $O P N$ expression, while the decreased expression of $A L P$ could be explained by a feedback mechanism where lower levels of PPi result in less ALP being needed to hydrolyse it to $\mathrm{Pi}$.

Comparatively little is known about the interdependence of ENPP1/ PC-1 and BMP2. BMP2 plays an essential role in the differentiation of MSCs towards bone, cartilage and connective tissue [60] and transcriptionally regulates $A L P$, collagen type 1, osteocalcin and $O P N$ [61]. 
Here, we found that silencing ENPP1 expression resulted in upregulation of BMP2 expression at gene and protein levels in in vitro osteogenic differentiation experiments.

We suggest that osteoinductive ceramics trigger the differentiation of hMSCs into the osteogenic lineage and therefore the expression of high levels of BMP2 and the onset of mineralisation. ENPP1 is expressed in response to this process in order to restrict further mineralisation. Therefore, silencing ENPP1 in cells cultured on osteoinductive materials might result in a more pronounced osteogenic differentiation and faster mineralisation in vitro.

We now consider the role of material properties in osteoinduction. As described above, the balance between PPi and Pi is important in the regulation of tissue mineralisation. This balance is also affected by the presence of $\mathrm{CaP}$ ceramics in the system, as these materials undergo a dynamic exchange of calcium and $\mathrm{Pi}$ with the cell culture medium. It should be noted that cell culture medium and body fluids are both supersaturated with respect to calcium and phosphate, so the dominant process is adsorption or precipitation of these ions from the medium onto the surface of the ceramic rather than dissolution of the ions from the ceramic into the medium. We found a difference in levels of calcium and phosphorus in the cell culture medium between osteoinductive TCP and non-osteoinductive HA, particularly after 2 days, with a significantly lower concentration of both elements in the presence of TCPa finding in accordance with previous results [62].

Interestingly, this study showed a heterogeneous distribution of PC1 in cells cultured on osteoinductive ceramics. Only cells in direct contact with the ceramic surface, not those in the ceramic pores, exhibited PC-1 positive staining. This suggests that direct contact with the ceramic surface is important for osteoinduction, as observed in earlier studies [12]. This effect could depend on the chemistry of the surface of the surface, its microstructure, or variations in local concentrations of soluble factors close to the surface.

We first investigated the importance of surface chemistry, by coating the surfaces of both osteoinductive TCP and non-osteoinductive HA with a collagen layer. No significant effect of the collagen coating on expression levels of ENPP1 and other osteogenic markers was observed, suggesting that replacing the CaP surface chemistry with that of collagen does not affect the differentiation of cells towards the osteogenic lineage. It should however be noted that the collagen coating was very thin, and probably unstable over a culture period of 7 days. This means that the replacement of CaP surface chemistry by collagen was only temporary, which may also explain why no significant differences were observed in calcium and phosphorus concentrations in the medium between the coated and uncoated ceramics. An experiment with a more stable coating that is able to affect ion exchange between the medium and the ceramics is needed to conclusively prove that replacement of the CaP surface chemistry with collagen does not affect the osteogenic differentiation of hMSCs.

Next, the effect of surface structure on osteogenic differentiation was investigated by replicating the surface microstructure of osteoinductive TCP and non-osteoinductive HA in polystyrene using micromoulding. Cell culture experiments showed a marked decrease in mRNA expression of ENPP1, BMP2 and OPN on the polystyrene replicas compared to the ceramic originals, and no difference in expression levels of these markers between the replicas of different ceramics. These results showed that microstructure alone, in the absence of $\mathrm{CaP}$, is not sufficient to trigger osteogenic differentiation. While these findings are in accordance with previous results regarding the expression of osteogenic markers by hMSCs cultured on polymer replicas of various calcium phosphate crystals [31], another study has shown that HA surfaces retain their positive effect on the expression of osteogenic markers after sputter-coating with gold to completely cover the surface [63].

Other studies have also shown that differentiation of hMSCs towards the osteogenic lineage can be triggered by nanotopographies fabricated from PMMA [64] or titanium [65], though neither of these studies measured an increase in ENPP1 or BMP2. In our study, structural ceramic replicas in polystyrene could not trigger the osteogenic differentiation, however, we have demonstrated the importance of surface microstructure in CaP ceramics. PC-1 expression was detected in cells in direct contact with the surface of the osteoinductive $\mathrm{BCP} 1150$, but not in the non-osteoinductive BCP1300. While these two ceramics are chemically identical, their microstructure is significantly different.

Taken together, these results support the hypothesis that a localised process involving exchange of calcium and phosphate ions between the medium (or body fluids) and the material is important for osteoinduction by CaP ceramics. In particular, given the supersaturation of cell culture medium with respect to these ions, we suggest that the mechanism involves localised depletion of calcium and/or phosphate ions as apatite is formed on the surface. Cells in direct contact with the material are most exposed to this localised depletion, and are the ones being triggered to differentiate into the osteogenic lineage first. As has been recently hypothesised [22], the microstructure of the material is important in determining whether there is sufficient replenishment of depleted ions from the bulk solution; insufficient replenishment will trigger an osteoinductive response, while sufficient replenishment will not. The results from the collagen-coated ceramics, that should be taken with caution because of the low thickness of the coating, could be explained by the fact that, though the CaP ceramic surface chemistry has been replaced, collagen is also a potential nucleation site for HA crystallisation, so a material with the microstructure of an osteoinductive $\mathrm{CaP}$ ceramic and the surface chemistry of collagen can itself be osteoinductive. On the other hand, the polystyrene replicas have the requisite microstructure but cannot nucleate HA crystallisation.

In this work, we focused on the role of chemistry and microstructure, based on the known mechanisms of ENPP1/PC1. However, it cannot be ignored that, by introducing a different chemistry, either through collagen coating or by replication in polystyrene, other properties of the surface, such as mechanical properties and wettability, may also change. Substrate stiffness versus $\mathrm{CaP}$ chemistry has previously been studied by Mattei and co-authors, who suggested that the presence of $\mathrm{CaP}$ has a stronger effect on osteogenic differentiation of human periosteum derived progenitor cells, but also that this effect can be enhanced by controlling substrate stiffness [66]. In our study, the CaP ceramics as well as their replicas in polystyrene are hard materials and it is not expected that they would have different mechanical effects on cells. Regarding collagen, in an earlier study it was shown that cells can sense the stiffness of the underlying substrate through a thin layer of collagen, suggesting that the mechanical effect of the collagen itself is limited. Nevertheless, in a paper by Mullen et al. it has been emphasized that a complex combination of the effects of substrate modulus, thickness, and microstructure needs to be taken into account to determine the mechanical forces experienced at the cellular level and therefore the mechanical effect of the collagen layer on cells cannot be fully excluded [67].

Wettability of the surface and specific surface area are also important, especially for the initial protein binding from serum-containing cell culture medium. We observed that both TCP and collagen-coated TCP immediately absorbed water droplets during contact angle measurements, because of their microporosity. Coating HA discs (contact angle $75.8^{\circ} \pm 10.8^{\circ}$ ) with collagen rendered them more hydrophilic $\left(41.2^{\circ} \pm 4.8^{\circ}\right)$. In contrast, polystyrene replicas were more hydrophobic, having a contact angle of $94.2^{\circ} \pm 9.8^{\circ}$ (Table S5). These differences, along with differences in the accessible surface area, could affect the quantity as well as the type and conformation of proteins binding to the surface, which in turn may affect cell attachment and subsequent biological processes and is a topic of further investigation.

In summary, this study describes for the first time a role for ENPP1/ PC-1 in the osteogenic differentiation of hMSCs cultured on osteoinductive CaP ceramics. ENPP1/PC-1 was found to be expressed exclusively in cells in direct contact with the surface of osteoinductive ceramics, suggesting that it is expressed in response to a, probably chemically-driven, process occurring at the surface. In addition, cells in 
which ENPP1 had been silenced expressed increased levels of BMP2, suggesting that ENPP1 acts to negatively regulate BMP2 expression as part of an inhibitory response to osteogenic differentiation and ectopic mineralisation at the surface of a ceramic.

This study provides important information about the interplay of genes and proteins involved in the regulation of the osteoinductive response to biomaterials, and also serves as supporting evidence for the theory that localised depletion of calcium and $\mathrm{Pi}$ ions is responsible for osteoinduction. This is useful knowledge for the rational design of future synthetic bone graft substitutes. Further work is needed to describe later events in the process of osteoinduction and biomineralisation at the protein level, and to elucidate the role of ENPP1 in later stages of the mechanism. For instance, it is as yet unknown whether ENPP1 has any role in extracellular matrix production, and longer-term cell culture experiments will be necessary to elucidate this. The chemistry occurring at the ceramic surface should be studied to determine exactly what leads to the differentiation of cells into the distinct PC- $1^{+}$subpopulation described in this study. Finally, in vivo osteoinduction experiments are important to conclusively demonstrate the importance of ENPP1 in osteoinduction by biomaterials.

\section{Author contributions}

$\mathrm{PH}$ and $\mathrm{ZO}$ designed the experiments, which $\mathrm{ZO}$ performed unless otherwise stated. HF performed the initial proteomic analysis. ZO and AJG performed the ENPP1 shRNA silencing experiments. TML performed the MS measurements. ZO and AA performed the PC-1 immunohistochemistry and Western blotting. ZO and DP produced the polystyrene microstructural replicas and performed the ICP-MS analyses. HY and ZO performed production and analysis of materials. $\mathrm{PH}$, $\mathrm{ZO}$ and APMG analysed and interpreted data and wrote the paper with input from all authors. All authors approved the final version of the manuscript.

\section{Data availability}

The data required to reproduce these findings cannot be shared at this time as the data also forms part of an ongoing study.

\section{Acknowledgements}

ZO acknowledges financial support by the Netherlands Science Organisation TA-COAST grant \# 05321104. APMG and PH acknowledge financial support by the Interreg Vlaanderen-Nederland Biomat on Microfluidic Chip collaboration. This research has been in part made possible with the support of the Dutch Province of Limburg. The authors declare no conflict of interest.

\section{Appendix A. Supplementary data}

Supplementary data to this article can be found online at https:// doi.org/10.1016/j.biomaterials.2019.04.021.

\section{References}

[1] E.H. Schemitsch, Size matters: defining critical in bone defect size!, J. Orthop. Trauma 31 (2017) S20-S22, https://doi.org/10.1097/BOT.0000000000000978.

[2] C.J. Damien, J.R. Parsons, Bone graft and bone graft substitutes: a review of current technology and applications, J. Appl. Biomater. 2 (1991) 187-208, https://doi.org/ 10.1002/jab.770020307

[3] P. Habibovic, H. Yuan, C.M. Van Der Valk, G. Meijer, C.A. Van Blitterswijk, K. De Groot, 3D microenvironment as essential element for osteoinduction by biomaterials, Biomaterials 26 (2005) 3565-3575, https://doi.org/10.1016/j.biomaterials. 2004.09.056.

[4] A.M.C. Barradas, V. Monticone, M. Hulsman, C. Danoux, H. Fernandes, Z. Tahmasebi Birgani, F. Barrère-De Groot, H. Yuan, M. Reinders, P. Habibovic, C. Van Blitterswijk, J. De Boer, Molecular mechanisms of biomaterial-driven osteogenic differentiation in human mesenchymal stromal cells, Integr. Biol. (United Kingdom) 5 (2013) 920-931, https://doi.org/10.1039/c3ib40027a.
[5] N. Eliaz, N. Metoki, Calcium phosphate bioceramics: a review of their history, structure, properties, coating technologies and biomedical applications, Materials 10 (2017), https://doi.org/10.3390/ma10040334.

[6] V.P. Galván-Chacón, P. Habibovic, Deconvoluting the bioactivity of calcium phosphate-based bone graft substitutes: strategies to understand the role of individual material properties, Adv. Healthc. Mater. 6 (2017) 1-15, https://doi.org/10.1002/ adhm.201601478.

[7] H. Yuan, J.D. de Bruijn, Y. Li, J. Feng, Z. Yang, K. De Groot, X. Zhang, Bone formation induced by calcium phosphate ceramics in soft tissue of dogs: a comparative study between porous $\alpha$-TCP and $\beta$-TCP, J. Mater. Sci. Mater. Med. 12 (2001) 7-13, https://doi.org/10.1021/es00042a612.

[8] U. Ripamonti, The morphogenesis of bone in replicas of porous hydroxyapatite obtained from conversion of calcium carbonate exoskeletons of coral, J. Bone Jt. Surg. 73 (1991) 692-703, https://doi.org/10.2106/00004623-199173050-00007.

[9] A.K. Gosain, L. Song, P. Riordan, M.T. Amarante, P.G. Nagy, C.R. Wilson, J.M. Toth, J.L. Ricci, A 1-year study of osteoinduction in hydroxyapatite biomaterials in an adult sheep model: Part 1, Plast. Reconstr. Surg. 109 (2002) 619-630.

[10] P. Habibovic, M.C. Kruyt, M.V. Juhl, S. Clyens, R. Martinetti, L. Dolcini, N. Theilgaard, C.A. Van Blitterswijk, Comparative in vivo study of six hydroxyapatite-based bone graft substitutes, J. Orthop. Res. 26 (2008) 1363-1370, https://doi.org/10.1002/jor.20648.

[11] P. Habibovic, J. Li, C.M. Van Der Valk, G. Meijer, P. Layrolle, C.A. Van Blitterswijk, K. De Groot, Biological performance of uncoated and octacalcium phosphate-coated Ti6Al4V, Biomaterials 26 (2005) 23-36, https://doi.org/10.1016/j.biomaterials. 2004.02.026.

[12] P. Habibovic, U. Gbureck, C.J. Doillon, D.C. Bassett, C.A. van Blitterswijk, J.E. Barralet, Osteoconduction and osteoinduction of low-temperature 3D printed bioceramic implants, Biomaterials 29 (2008) 944-953, https://doi.org/10.1016/j. biomaterials.2007.10.023.

[13] U. Ripamonti, J. Crooks, A.N. Kirkbride, Sintered porous hydroxyapatites with intrinsic osteoinductive activity: geometric induction of bone formation, S. Afr. J. Sci. 95 (1999) 335-343

[14] T. Nasu, M. Takemoto, N. Akiyama, S. Fujibayashi, M. Neo, T. Nakamura, EP4 agonist accelerates osteoinduction and degradation of P-tricalcium phosphate by stimulating osteoclastogenesis, J. Biomed. Mater. Res. A 89 (2009) 601-608, https://doi.org/10.1002/jbm.a.31984.

[15] I. El Bialy, W. Jiskoot, M. Reza Nejadnik, Formulation, delivery and stability of bone morphogenetic proteins for effective bone regeneration, Pharm. Res. 34 (2017) 1152-1170, https://doi.org/10.1007/s11095-017-2147-x.

[16] B.H. Fellah, N. Josselin, D. Chappard, P. Weiss, P. Layrolle, Inflammatory reaction in rats muscle after implantation of biphasic calcium phosphate micro particles, J. Mater. Sci. Mater. Med. 18 (2007) 287-294, https://doi.org/10.1007/s10856-0060691-8.

[17] B.H. Fellah, B. Delorme, J. Sohier, D. Magne, P. Hardouin, P. Layrolle, Macrophage and osteoblast responses to biphasic calcium phosphate microparticles, J. Biomed. Mater. Res. A 93 (2010) 1588-1595, https://doi.org/10.1002/jbm.a.32663.

[18] H. Yamasaki, H. Sakai, Osteogenic response to porous hydroxyapatite ceramics under the skin of dogs, Biomaterials 13 (1992) 308-312, https://doi.org/10.1016/ 0142-9612(92)90054-R

[19] H. Yuan, K. Kurashina, J.D. De Bruijn, Y. Li, K. De Groot, X. Zhang, A preliminary study on osteoinduction of two kinds of calcium phosphate ceramics, Biomaterials 20 (1999) 1799-1806.

[20] A.M.C. Barradas, H. Yuan, C.A. van Blitterswijk, P. Habibovic, Osteoinductive biomaterials: current knowledge of properties, experimental models and biological mechanisms, Eur. Cells Mater. 21 (2011) 407-429, https://doi.org/10.22203/eCM. v021a31.

[21] W. Habraken, P. Habibovic, M. Epple, M. Bohner, Calcium phosphates in biomedical applications: materials for the future? Mater. Today 19 (2016) 69-87, https:// doi.org/10.1016/j.mattod.2015.10.008.

[22] M. Bohner, R.J. Miron, A proposed mechanism for material-induced heterotopic ossification, Mater. Today. (n.d.). doi:10.1016/j.mattod.2018.10.036.

[23] N. Groen, N. Tahmasebi, F. Shimizu, Y. Sano, T. Kanda, D. Barbieri, H. Yuan, P. Habibovic, C.A. van Blitterswijk, J. de Boer, Exploring the material-induced transcriptional landscape of osteoblasts on bone graft materials, Adv. Healthc. Mater. 4 (2015) 1691-1700, https://doi.org/10.1002/adhm.201500171.

[24] J.W. Goding, B. Grobben, H. Slegers, Physiological and pathophysiological functions of the ecto-nucleotide pyrophosphatase/phosphodiesterase family, Biochim Biophys. Acta - Mol. Basis Dis. 1638 (2003) 1-19, https://doi.org/10.1016/S0925 4439(03)00058-9.

[25] R. Sapir-Koren, G. Livshits, Bone mineralization and regulation of phosphate homeostasis, IBMS BoneKEy 8 (2011) 286-300, https://doi.org/10.1138/ 20110516.

[26] C. Stefan, S. Jansen, M. Bollen, NPP-type ectophosphodiesterases: unity in diversity, Trends Biochem. Sci. 30 (2005) 542-550, https://doi.org/10.1016/j.tibs.2005.08. 005.

[27] A.M. Ho, M.D. Johnson, D.M. Kingsley, Role of the mouse ank gene in control of tissue calcification and arthritis, Science 289 (2000) 265-270, https://doi.org/10. 1126/science.289.5477.265 (80-. ).

[28] F.T. Hakim, R. Cranley, K.S. Brown, E.D. Eanes, L. Harne, J.J. Oppenheim, Hereditary joint disorder in progressive ankylosis (ank/ank) mice I. association of calcium hydroxyapatite deposition with inflammatory arthropathy, Arthritis Rheum. 27 (1984) 1411-1420, https://doi.org/10.1002/art.1780271212.

[29] Y. Jin, Q. Cong, J. Gvozdenovic-Jeremic, J. Hu, Y. Zhang, R. Terkeltaub, Y. Yang, Enpp1 inhibits ectopic joint calcification and maintains articular chondrocytes by repressing hedgehog signaling, Development 145 (2018), https://doi.org/10.1242/ dev.164830 dev164830. 
[30] H. Yuan, H. Fernandes, P. Habibovic, J. de Boer, A.M.C. Barradas, A. de Ruiter, W.R. Walsh, C.A. van Blitterswijk, J.D. de Bruijn, Osteoinductive ceramics as a synthetic alternative to autologous bone grafting, Proc. Natl. Acad. Sci. 107 (2010) 13614-13619, https://doi.org/10.1073/pnas.1003600107.

[31] C. Danoux, L. Sun, G. Koçer, Z.T. Birgani, D. Barata, J. Barralet, C. Van Blitterswijk, R. Truckenmüller, P. Habibovic, Development of highly functional biomaterials by decoupling and recombining material properties, Adv. Mater. 28 (2016) 1803-1808, https://doi.org/10.1002/adma.201504589.

[32] L. Sun, C. Danoux, Q. Wang, D. Pereira, D. Barata, J. Zhang, V. LaPointe, R. Truckenmüller, C. Bao, X. Xu, P. Habibović, Independent effects of the chemical and microstructural surface properties of polymer/ceramic composites on proliferation and osteogenic differentiation of human MSCs, Acta Biomater. 42 (2016) 364-377, https://doi.org/10.1016/j.actbio.2016.06.018.

[33] N. Groen, H. Yuan, D.G.A.J. Hebels, G. Koçer, F. Mbuyi, V. LaPointe, R. Truckenmüller, C.A. van Blitterswijk, P. Habibović, J. de Boer, Linking the transcriptional landscape of bone induction to biomaterial design parameters, Adv. Mater. 29 (2017), https://doi.org/10.1002/adma.201603259.

[34] R. Craig, R.C. Beavis, A method for reducing the time required to match protein sequences with tandem mass spectra, Rapid Commun. Mass Spectrom. 17 (2003) 2310-2316, https://doi.org/10.1002/rcm.1198.

[35] B.C. Searle, M. Turner, A.I. Nesvizhskii, Improving sensitivity by probabilistically combining results from multiple MS/MS search methodologies, J. Proteome Res. 7 (2008) 245-253, https://doi.org/10.1021/pr070540w.

[36] A. Keller, A.I. Nesvizhskii, E. Kolker, R. Aebersold, Empirical statistical model to estimate the accuracy of peptide identifications made by MS/MS and database search, Anal. Chem. 74 (2002) 5383-5392, https://doi.org/10.1021/ac025747h.

[37] A.I. Nesvizhskii, A. Keller, E. Kolker, R. Aebersold, A statistical model for identifying proteins by tandem mass spectrometry, Anal. Chem. 75 (2003) 4646-4658 https://doi.org/10.1021/ac0341261.

[38] B.C. Searle, Scaffold: a bioinformatic tool for validating MS/MS-based proteomic studies, Proteomics 10 (2010) 1265-1269, https://doi.org/10.1002/pmic. 200900437.

[39] C. Stingl, F.G.I. Van Vilsteren, C. Guzel, F.J.W. Kate, M. Visser, K. Kausilia, J.J. Bergman, T.M. Luider, Reproducibility of protein identification of selected cell types in Barrett's esophagus analyzed by combining laser-capture microdissection and mass spectrometry, J. Proteome Res. 10 (2011) 288-298.

[40] A.J. Groot, R. Habets, S. Yahyanejad, C.M. Hodin, K. Reiss, P. Saftig, J. Theys, M. Vooijs, Regulated proteolysis of NOTCH2 and NOTCH3 receptors by ADAM10 and presenilins, Mol. Cell Biol. 34 (2014) 2822-2832, https://doi.org/10.1128/ MCB.00206-14.

[41] K. Kato, H. Nishimasu, S. Okudaira, E. Mihara, R. Ishitani, J. Takagi, J. Aoki, O. Nureki, Crystal structure of Enpp1, an extracellular glycoprotein involved in bone mineralization and insulin signaling, Proc. Natl. Acad. Sci. 109 (2012) 16876-16881, https://doi.org/10.1073/pnas.1208017109.

[42] H.K. Nam, J. Liu, Y. Li, A. Kragor, N.E. Hatch, Ectonucleotide pyrophosphatase/ phosphodiesterase-1 (ENPP1) protein regulates osteoblast differentiation, J. Biol. Chem. 286 (2011) 39059-39071, https://doi.org/10.1074/jbc.M111.221689.

[43] J.K.D. Villa, M.A.N. Diaz, V.R. Pizziolo, H.S.D. Martino, Effect of vitamin K in bone metabolism and vascular calcification: a review of mechanisms of action and evidences, Crit. Rev. Food Sci. Nutr. 57 (2017) 3959-3970, https://doi.org/10.1080/ 10408398.2016 .1211616$.

[44] W. Zhu, P.G. Robey, A.L. Boskey, The regulatory role of matrix proteins in mineralization of bone, in: R. Marcus, D. Feldman, D.A. Nelson, C.J. Rosen (Eds.), Fundam. Osteoporos. Academic Press, Cambridge, MA, 2009, pp. 153-202.

[45] C. Danoux, D. Pereira, N. Döbelin, C. Stähli, J. Barralet, C. van Blitterswijk, P. Habibovic, The effects of crystal phase and particle morphology of calcium phosphates on proliferation and differentiation of human mesenchymal stromal cells, Adv. Healthc. Mater. 5 (2016) 1775-1785, https://doi.org/10.1002/adhm. 201600184

[46] N.L. Davison, X. Luo, T. Schoenmaker, V. Everts, H. Yuan, F. Barrère-de Groot, J.D. de Bruijn, Submicron-scale surface architecture of tricalcium phosphate directs osteogenesis in vitro and in vivo, Eur. Cells Mater. 27 (2014) 281-297, https://doi. org/10.22203/eCM.v027a20.

[47] N.L. Davison, J. Su, H. Yuan, J.J.J.P. van den Beucken, J.D. De Bruijn, F. Barrere-de Groot, Influence of surface microstructure and chemistry on osteoinduction and osteoclastogenesis by biphasic calcium phosphate discs, Eur. Cells Mater. 29 (2015) 314-329.

[48] R.D.A.M. Alves, M. Eijken, S. Swagemakers, H. Chiba, M.K. Titulaer, P.C. Burgers, T.M. Luider, J.P.T.M. Van Leeuwen, Proteomic analysis of human osteoblastic cells: relevant proteins and functional categories for differentiation, J. Proteome Res. 9
(2010) 4688-4700, https://doi.org/10.1021/pr100400d.

[49] Y. Nitschke, F. Rutsch, Genetics in arterial calcification: lessons learned from rare diseases, Trends Cardiovasc. Med. 22 (2012) 145-149, https://doi.org/10.1016/j. tcm.2012.07.011.

[50] N.C.W. Mackenzie, C. Huesa, F. Rutsch, V.E. MacRae, New insights into NPP1 function: lessons from clinical and animal studies, Bone 51 (2012) 961-968, https://doi.org/10.1016/j.bone.2012.07.014.

[51] N.C.W. Mackenzie, D. Zhu, E.M. Milne, R. van't Hof, A. Martin, D.L. Quarles, J.L. Millán, C. Farquharson, V.E. MacRae, Altered bone development and an increase in FGF-23 expression in Enpp1-/-mice, PLoS One 7 (2012), https://doi.org/ 10.1371/journal.pone.0032177.

[52] K. Johnson, A. Moffa, Y. Chen, K. Pritzker, J. Goding, R. Terkeltaub, Matrix vesicle plasma cell membrane glycoprotein-1 regulates mineralization by murine osteoblastic MC3T3 cells, J. Bone Miner. Res. 14 (1999) 883-892.

[53] K.A. Johnson, L. Hessle, S. Vaingankar, C. Wennberg, S. Mauro, S. Narisawa, J.W. Goding, K. Sano, J.L. Millan, R. Terkeltaub, Osteoblast tissue-nonspecific alkaline phosphatase antagonizes and regulates PC-1, Am. J. Physiol. Integr. Comp. Physiol. 279 (2000) R1365-R1377, https://doi.org/10.1152/ajpregu.2000.279.4. R1365.

[54] D. Harmey, L. Hessle, S. Narisawa, K.A. Johnson, R. Terkeltaub, J.L. Millán Concerted regulation of inorganic pyrophosphate and osteopontin by Akp2, Enpp1, and ank: an integrated model of the pathogenesis of mineralization disorders, Am. J. Pathol. 164 (2004) 1199-1209, https://doi.org/10.1016/S0002-9440(10) 63208-7.

[55] C.L. Hammond, S. Schulte-Merker, Two populations of endochondral osteoblasts with differential sensitivity to Hedgehog signalling, Development 136 (2009) 3991-4000, https://doi.org/10.1242/dev.042150.

[56] S. Bin Sulaiman, T.K. Keong, C.H. Cheng, A. Bin Saim, R.B. Hj Idrus, Tricalcium phosphate/hydroxyapatite (TCP-HA) bone scaffold as potential candidate for the formation of tissue engineered bone, Indian J. Med. Res. 137 (2013) 1093-1101, https://doi.org/10.1002/elan.201000094.

[57] K.A. Johnson, J. Goding, D.V.A.N. Etten, A. Sali, S. Hu, L. Milla, D. Farley, H. Krug, L. Hessle, R. Terkeltaub, Linked deficiencies in extracellular PPi and osteopontin mediate pathologic calcification associated with defective PC-1 and ANK expression, J. Bone Miner. Res. 18 (2003) 994-1004.

[58] M.Y. Speer, M.D. McKee, R.E. Guldberg, L. Liaw, H.-Y. Yang, E. Tung, G. Karsenty, C.M. Giachelli, Inactivation of the osteopontin gene enhances vascular calcification of matrix Gla protein-deficient mice, J. Exp. Med. 196 (2002) 1047-1055, https:// doi.org/10.1084/jem.20020911.

[59] F. Rutsch, Y. Nitschke, R. Terkeltaub, Genetics in arterial calcification: pieces of a puzzle and cogs in a wheel, Circ. Res. 109 (2011) 578-592, https://doi.org/10. 1161/CIRCRESAHA.111.247965.

[60] A. Yamaguchi, K. Sakamoto, T. Minamizato, K. Katsube, S. Nakanishi, Regulation of osteoblast differentiation mediated by BMP, Notch, and CCN3/NOV, Jpn. Dent. Sci. Rev. 44 (2008) 48-56, https://doi.org/10.1016/j.jdsr.2007.11.003.

[61] N. Sykaras, L.A. Opperman, Bone morphogenetic proteins (BMPs): how do they function and what can they offer the clinician? J. Oral Sci. 45 (2003) 57-73.

[62] Z.T. Birgani, A. Malhotra, C.A. van Blitterswijk, P. Habibovic, Human mesenchymal stromal cells response to biomimetic octacalcium phosphate containing strontium, J. Biomed. Mater. Res. A 104 (2016) 1946-1960, https://doi.org/10.1002/jbm.a. 35725 .

[63] E. Pegg, F. Matboli, T. Marriott, I. Khan, C.A. Scotchford, Topographical and chemical effects of electrochemically assisted deposited hydroxyapatite coatings on osteoblast-like cells, J. Biomater. Appl. 28 (2014) 946-953.

[64] M.J. Dalby, N. Gadegaard, R. Tare, A. Andar, M.O. Riehle, P. Herzyk, C.D.W. Wilkinson, R.O.C. Oreffo, The control of human mesenchymal cell differentiation using nanoscale symmetry and disorder, Nat. Mater. 6 (2007) 997-1003, https://doi.org/10.1038/nmat2013.

[65] R.A. Gittens, T. McLachlan, Y. Cai, S. Berner, R. Tannenbaum, Z. Schwartz, K.H. Sandhage, B.D. Boyan, The effects of combined micron-/submicron-scale surface roughness and nanoscale features on cell proliferation and differentiation, Biomater. Sci. 32 (2011) 3395-3403, https://doi.org/10.1016/j.biomaterials.2011. 01.029.

[66] G. Mattei, C. Ferretti, A. Tirella, A. Ahluwalia, M. Mattioli-Belmonte, Decoupling the role of stiffness from other hydroxyapatite signalling cues in periosteal derived stem cell differentiation, Sci. Rep. 5 (2015) 10778, https://doi.org/10.1038/ srep10778.

[67] C.A. Mullen, T.J. Vaughan, K.L. Billiar, L.M. McNamara, The effect of substrate stiffness, thickness, and cross-linking density on osteogenic cell behavior, Biophys. J. 108 (2015) 1604-1612, https://doi.org/10.1016/j.bpj.2015.02.022. 